\title{
Modern microbial mats from the Chihuahuan Desert provide insights into ecological stability throughout Earth's history
}

\author{
David Madrigal-Trejo, Jazmín Sánchez-Pérez, Laura Espinosa-Asuar, \\ Valeria Souza
}

\begin{abstract}
Microbial mats are complex ecological assemblages that are found in the Precambrian fossil record and in extant extreme environments. Hence, these structures are regarded as highly stable ecosystems. In this work, we assess the ecological stability in a modern, fluctuating, hypersaline pond from the Cuatro Ciénegas Basin. From the 2016 to 2019 metagenomic sampling of this site, we found that this microbial site is sensitive to disturbances, which leads to high taxonomic replacement. Additionally, the mats have shown to be functionally stable throughout time, and could be differentiated between dry and rainy seasonal states. We speculate that this microbial system could represent modern analogs of ancient microbial mats where functions were preserved over time, whereas composition was subject to diversification in the face of local and planetary perturbations.
\end{abstract}

\section{Introduction}

There is little to no doubt that life emerged early in Earth's history, as suggested by geochemical signatures, biomarkers, microfossils and sedimentary structures from the early Archean (Lepot, 2020). Particularly, phototrophic microbial mats, alongside stromatolites, have been extensively present in the Archean rock record, as shown in the fossil evidence from the Dresser formation (3.48 Ga) (Noffke, Christian, et al., 2013), the Buck Reef Chert (3.42 Ga) (Tice and Lowe, 2004; Tice, 2009) , and the Moodies group (3.22 Ga) (Noffke, Eriksson, et al., 2006; Homann, Heubeck, et al., 2015; Homann, Sansjofre, et al., 2018). Microbial mats are also found in modern environments; they are benthic, stratified, and self-sustaining biological communities of thousands of phylogenetically diverse microorganisms embedded in a matrix of extracellular polymeric substances (EPS) (Prieto-Barajas et al., 2018). Therefore, it is straightforward to infer that microbial mats have been thriving on Earth for more than $\sim 3.5 \mathrm{Ga}$, in spite of every threat posed to life.

Indeed, Earth's history has been marked with gradual transitions and punctuated events that certainly disturbed the early biosphere. The early Sun, although $30 \%$ fainter than today, emitted highfrequency radiation, coronal mass ejections and solar cosmic rays by 2-3 orders of magnitude greater than present values (Obridko et al., 2020); geomagnetic polarity transitions would increase the solar wind and cosmic rays flux (Erdmann et al., 2021); asteroid impacts of bolides of 20-70 km in diameter struck Earth at 3.47-3.23 Ga and possibly until 3.0 Ga, way after the Late Heavy Bombardment (Lowe et al., 2014; Davatzes et al., 2019); surface chemistry shifted from a reduced state towards an oxidized world during the Grate Oxidation Event (2.43-2.22 Ga) (Gumsley, Chamberlain, et al., 2017; Poulton et al., 2021); global glaciation events were triggered by changes in the carbon cycle and solar heating (Tajika, 2007; Arnscheidt and Rothman, 2020); and large igneous provinces flooded the surface with effusive volcanism towards the end of the Archean and during the Phanerozoic (Mole et al., 2018; 
Gumsley, Stamsnijder, et al., 2020). Each of these environmental pressures could potentially erradicate life from Earth, yet, life (as we know it) survived.

The success of microbial mats and stromatolites as biological structures can only be understood in terms of ecological stability; namely, the community response to disturbances, which could be dissected into the degree to which a community is insensitive to perturbations (ecological resistance) and the rate at which a community restores to the pre-disturbed state (ecological resilience) (Shade et al., 2012; Song et al., 2015). Environmental disturbances can be classified into pulses and presses if the perturbation is a discrete, short-term event, or a continuous, long-term transition, respectively (Bender et al., 1984; Shade et al., 2012). Microbial community stability is a topic of interest for a wide array of systems and disturbances, such as dry-rewetting events (Kolda et al., 2019), differences in water level (Ren et al., 2019), temperature variations (García-García et al., 2019; Okonkwo et al., 2020), chemical stress (Jiang et al., 2020), shifting redox patterns (Pett-Ridge and Firestone, 2005), and changes in salinity (Berga et al., 2017). Nonetheless, microbial community stability under the scope of early life geobiology is rarely explored.

In this work, we study the microbial system denominated as the Archean Domes, Cuatro Ciénegas, Mexico (Fig. 1). This pond is subject to extreme conditions, such as prolonged droughts, intense solar radiation, and major shifts in salinity and $\mathrm{pH}$. Hypersaline microbial mats are among the best studied type of mats, and they have been widely recognized as analogs to the Archean Earth and, plausibly, early Mars (Wong, Smith, et al., 2015; Perl and Baxter, 2020; Saona et al., 2020). Hence, we took a metagenomic, uniformitarian approach to assess ecological stability and community dynamics from a three-year sampling to speculate the underlying processes and mechanisms that enable microbial communities to cope with multiple disturbances throughout Earth's history.

\section{Materials and methods}

\subsection{Study site and sample collection}

The Archean Domes (26-49'41.7'N, 102 $\left.{ }^{\circ} 01^{\prime} 28.7^{\prime \prime} \mathrm{W}\right)$ is a seasonal, water-fluctuating pond in Rancho Pozas Azules from Pronatura located at the eastern side of the Cuatro Ciénegas Basin, Coahuila, México (Site overview in Fig. S1: Supplementary material). This site was discovered in 2016, and was firstly described by Medina-Chávez et al. (2019) [unpublished], and Espinosa-Asuar et al. (2021) [unpublished]. During the rainy season, mostly during the months of August to September, the pond fills with water up to $\sim 20 \mathrm{~cm}$. Green mats emerge over the soil surface, building dome-like sedimentary structures up to 10-15 cm in diameter (Fig. 1b,c). From November to July, water evaporates and salt precipitation covers the pond completely, burying the microbial mats (Fig. 1a). Salinity is variable between the two states, transitioning from 52.5 PSU (as measured in the rainy season of 2016) when filled with water to salt saturation during the dry season. From a recent sampling in September 2021, we observed that green mats and gas filled structures start to quickly develop after the day of rainfall. Inside the domes and mats there are variable concentrations of methane $(2.6-19.6 \mu \mathrm{g} / \mathrm{L}$ on the rainy season of 2016, 102-402 $\mu \mathrm{g} / \mathrm{L}$ on the dry season of 2017) and carbon dioxide (1.08-1.40 on the dry season of 2017). During dry season, $\mathrm{pH}$ is $\sim 7$, while on rainy season the $\mathrm{pH}$ rises to $\sim 8.5-9.5$ with the dissolution of salts.

We collected six samples of mats and associated sediment across a three-year period. During this time span, we got to collect three samples of each seasonal state: dry and rainy season. The mats from the dry season are from the sampling of April 2016, February 2017 and March 2019 (hereinafter denoted as M1_D16, M3_D17 and M5_D19, respectively). Mats from the rainy season are from the sampling of October 2016, October 2018 and September 2019 (hereinafter denoted as M2_R16, M4_R18 
bioRxiv preprint doi: https://doi.org/10.1101/2021.11.18.469043; this version posted November 21, 2021. The copyright holder for this preprint (which was not certified by peer review) is the author/funder, who has granted bioRxiv a license to display the preprint in perpetuity. It is made available under aCC-BY-ND 4.0 International license.

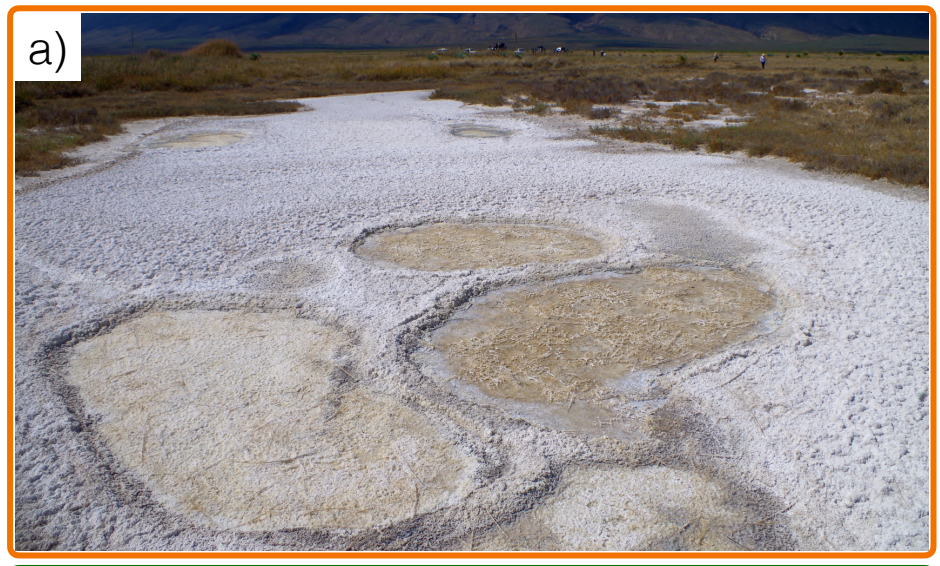

d)
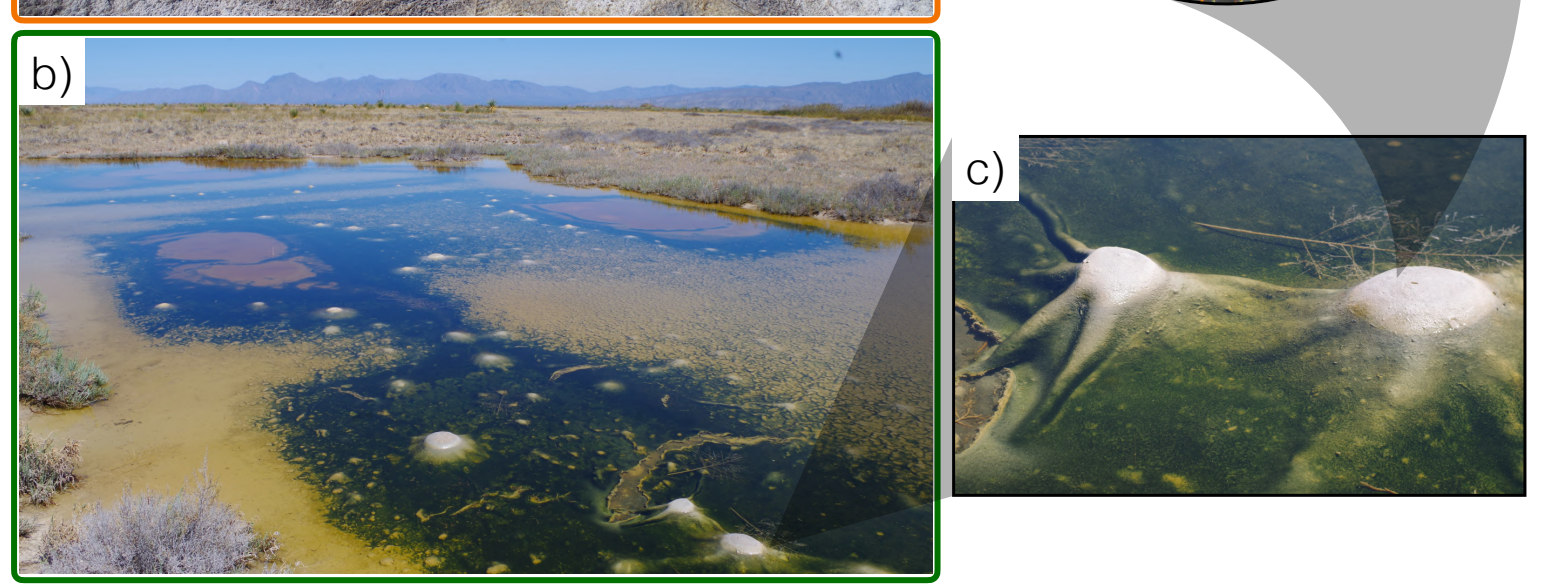

Fig. 1: The Archean Domes microbial system. The pond displays different features during a) dry season (sampling of March 2019) and b) rainy season (sampling of March 2016). c) Detail of the dome structures. d) 10X magnification of a microbial mat; functional stratification and sediment grains can be appreciated at this scale. 
and M6_R19, respectively). Rainy season samples come directly from developing domes, whereas dry season samples derive from soil regions where mat was visible to the naked eye. As the rainy season is heavily contingent on the cyclone dynamics of the Gulf of Mexico, samples were taken at different times, 1-2 weeks after a heavy rainfall to ensure a high level of water in the pond. To prevent contamination, samples were collected with gloves, sterile forceps and sterile conical tubes $(50 \mathrm{~mL})$ and stored in liquid nitrogen for their preservation prior to extract the DNA. Weather parameters were taken from the National Meteorological Service, CONAGUA, at the EMA station No. 15DBB372 in Cuatro Ciénegas $\left(27^{\circ} 0^{\prime} 7.2^{\prime \prime} \mathrm{N}, 102^{\mathrm{O}} 4^{\prime} 22.7^{\prime \prime} \mathrm{W}\right)$. Weather data is provided in Fig. S2 and Table S1: Supplementary material.

\subsection{DNA purification and sequencing}

From each sample, only the mat layer $(\sim 1 \mathrm{~cm})$ was taken for DNA extraction. As the samples of the dry seasons contain a thick layer of salt, this layer had to be separated with a sterile scalpel to facilitate the extraction. We perform the extraction of total DNA from the six samples as reported in Purdy (2005). Purified DNA was sent to CINVESTAV-LANGEBIO for shotgun metagenomic sequencing. DNA libraries for Illumina paired-end sequencing were prepared for each sample without any amplification step. DNA from all samples was sequenced with Illumina MiSeq $(2 \times 300$ base pair paired-end reads). The total number of paired-end reads per metagenome range from 4.7 to $28.0 \mathrm{Gbp}$ per library and orientation (forward and reverse). Number of raw reads can be found in Table S2: Supplementary material.

\subsection{Quality control, assembly and annotation of metagenomes}

We preprocessed the raw reads with Trimmomatic v0.38 (Bolger et al., 2014) with a sliding window of 4 , a Phred quality score of 30 , minimum length of 35 , and an average mean quality of 28 . For each metagenome, reads were assembled into contigs to facilitate gene prediction. Forward and reverse paired reads, and individual forward and reverse with no pair, were assembled using MEGAHIT v1.1.1 (Li, Liu, et al., 2015) with minimum contig length of 500, k-min of 27 and k-step of 10 as suggested for highly-diverse metagenomes (Bandla et al., 2020; Yan et al., 2021). To control for sequencing depth bias, we used the minimum number of reads $(1,288,875$ reads) to sample the metagenomic datasets at random to normalize coverage for comparisons. Unassembled reads were collected with BBtools (Bushnell, 2020) and SAMtools v1.12 (Li, Handsaker, et al., 2009). For assembled contigs, gene prediction and subsequent taxonomic annotation was done with CAT v5.2 (Meijenfeldt et al., 2019). Additional information regarding quality control, metagenome assembly, processing of not assembled reads with MEGAHIT, and taxonomic annotation can be found in Table S2-S5: Supplementary material. CAT is a robust taxonomic annotator that integrates known software programs such as gene predictor Prodigal (Hyatt et al., 2010) and gene annotator DIAMOND (Buchfink et al., 2014) against the NCBI nonredundant database (NCBI Resource Coordinators, 2018) to give a deep gene taxonomic annotation. Since taxonomic annotation with CAT revolves against all kinds of predicted genes, we also used six ribosomal protein families (PF00177, PF00298, PF00573, PF00237, PF00163 and PF00318) to validate CAT results. We downloaded ribosomal genes' seeds from Pfam database (Mistry et al., 2021). HMM profiles were built with HMMER v3.3 (Eddy, 2011), and hmmsearch was performed against all metagenomes (e-value $10^{-6}$ ). Ribosomal genes were annotated with DIAMOND, coupled with the NCBI non-redundant database. Overall functional profiling was done with SUPER-FOCUS (Silva et al., 2016) against the NCBI non-redundant database. We select resistance genes based on GO classification and download the amino acid sequences from UniProt database. Resistance query sequences were aligned with BLAST against all metagenomes. Finally, We selected key energy metabolisms and 
nutrient cycling as in Gutiérrez-Preciado et al. (2018). Protein families involved in each metabolic pathway were initially searched in UniProt (Bateman et al., 2021) and KEGG (Kanehisa et al., 2016) databases, and subsequently downloaded from Pfam. HMMER and BLAST (Altschul et al., 1990) analyses were performed for each protein family and for each metabolic pathway.

\subsection{Normalization, statistical analyses and data visualization}

We used R programming language (R Core Team, 2020) to run each statistical analysis, to normalize data and to generate figures. We list the libraries used as follows: ggplot2 v3.3.5 (Wickham, 2016) for overall plots, edgeR v3.34.1 for data normalization (Robinson et al., 2010), RAM v1.2.1.7 (Chen, Simpson, et al., 2018) for PCoA, PCA and CCA analyses, vegan v2.5-7 (Oksanen et al., 2020) for rarefaction curves and alpha-diversity metrics, UpSetR v1.4.0 (Lex et al., 2014) for upset plots, for differential expression analysis DESeq2 v1.32.0 (Love et al., 2014) and EnhancedVolcano v1.10.0 (Blighe et al., 2021), patchwork v1.1.1 (Pedersen, 2020) and fmsb v0.7.1 (Nakazawa, 2021) for radar charts, streamgraph v0.9.0 (Rudis, 2019) for streamgraphs, easyalluvial v0.3.0 (Koneswarakantha, 2021a) and parcats v0.0.3 (Koneswarakantha, 2021b) for alluvial plots, NetCoMi v1.0.2 for network analyses (Peschel et al., 2021), and umap v0.2.7.0 and dbscan v1.1-8 for clustering. Libraries BBmisc v1.11 (Bischl et al., 2017), dplyr v1.07 (Wickham et al., 2021), tidyr v1.1.4 (Wickham, 2021) were used for data manipulation. Gene abundances were normalized with the Relative Log Expression (RLE) method. PCoA and NMDS analyses for taxonomic groups were calculated with a Bray-Curtis measure. NetCoMi networks were built using SparCC measure, Bayesian-multiplicative replacement for zero handling and association threshold of 0.5. Phylum-level networks were built with the top 120 phyla, while genus-level networks were built with all the 250 core genera.

\section{Results}

\subsection{Taxonomical characterization}

We build rarefaction curves to evaluate diversity coverage for all samples. For genera richness, each sample reaches saturation and comparisons between them is suitable (Fig. 3S: Supplementary material). Open read-frames were predicted for reads, and further annotated for taxonomic classification with CAT. We detected 162 phyla, 2250 genera (across all samples), and more than 8,000 phylotypes per sample. Nevertheless, only $30-58 \%$ of the total predicted genes for each sample were classified, suggesting a considerable amount of potential novel taxonomic groups, which comprise the so called "microbial dark matter". These potentially uncultured organisms have shown to be of importance in other hypersaline microbial mats (Wong, MacLeod, et al., 2020). Mean abundances per domain show consistent results between CAT and ribosomal gene annotation; for CAT taxonomic assignment we got mean abundances of: $85.24 \%$ for Bacteria, $14.43 \%$ for Archaea, and 0.3\% for Eukaryota; whereas ribosomal gene annotation showed: $86.56 \%$ for Bacteria, $13.35 \%$ for Archaea, and $0.08 \%$ for Eukaryota.

Regarding the taxonomic composition, at the phylum level, samples consistently displayed Proteobacteria (23.51\%), Euryarchaeota (11.42\%), Bacteroidetes (10.26\%), Firmicutes (4.35\%), Cyanobacteria (3.30\%), Spirochaetes (2.84\%), Planctomycetes (1.99) and Chloroflexi (1.42) as the most abundant phyla (Fig. 2). The taxonomic annotation with ribosomal genes is also consistent with the phyla relative abundances of CAT annotation (taxonomic profile based on ribosomal proteins is shown in Figure S4: Supplementary material). Taxonomic profiles seem to vary between each sample; most noticeable, with the increase of Euryarchaeota for the 2019 samples. Overall, the Archean Domes have a high diversity as seen in Chao (143-271), Shannon (2.5-3.1) and inverse Simpson (4.6-8.3) indexes. 
bioRxiv preprint doi: https://doi.org/10.1101/2021.11.18.469043; this version posted November 21, 2021. The copyright holder for this preprint (which was not certified by peer review) is the author/funder, who has granted bioRxiv a license to display the preprint in perpetuity. It is made available under aCC-BY-ND 4.0 International license.

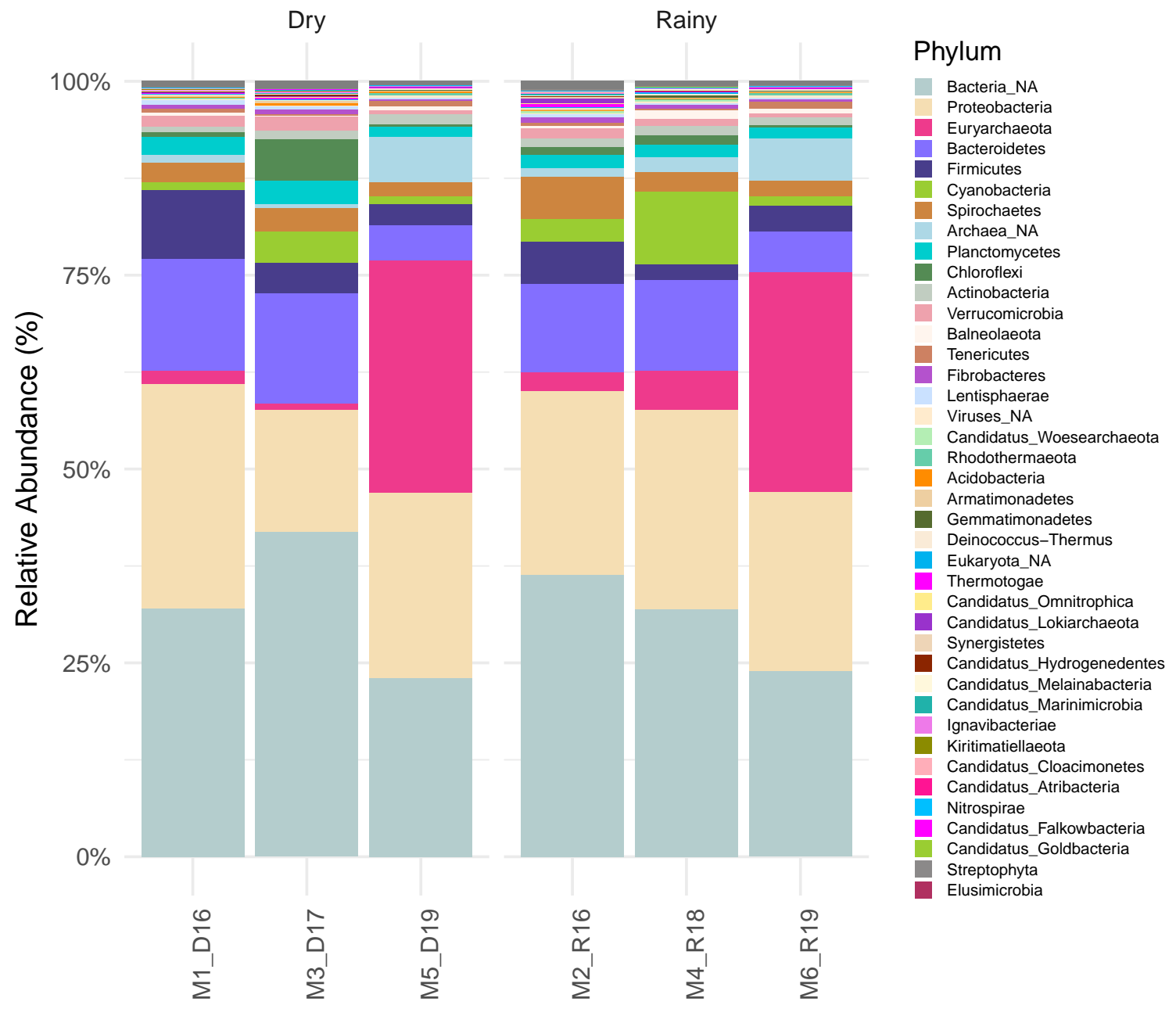

Fig. 2: Taxonomic profile of the Archean Domes. Only the top abundant phyla are displayed. Not annotated phyla were grouped into NA category. 
At the genus level, we find Coleofasciculus as the most abundant Cyanobacteria between all samples, which is widely known as a key mat-forming genus in sandy environments (Noffke, 2010; Ramos et al., 2017; Prieto-Barajas et al., 2018; Cardoso et al., 2019). Other cyanobacterial genera such as Leptolyngbya, Halothece, and Phormidium are also abundant between samples, and have also been previously reported in microbial mats (Ramos et al., 2017; Sohm et al., 2020; Brenes-Guillén et al., 2021). Anaerobic, halophilic, sulfate-reducing members of the Deltaproteobacteria such as Desulfonatronovibrio, Desulfonatronospira and Desulfovermiculus also appear in abundance in the Archean Domes samples.

(Kuever, 2014). Other relevant taxonomic genera present in the samples include Halorubrum (Euryarchaeota), Halanaerobium (Firmicutes), Spirocheta (Spirochetes), Chitinispirillum (Fibrobacteres), and Tangfeifania (Bacteroidetes). From the 2250 total genera found in the system, only between 16-19 for each sample belong to the abundant genera, that is, with an abundance $>1 \%$. In contrast, between 426-619 genera have abundances $<0.1 \%$, and belong to the so called "rare biosphere". Rare taxa account for the $11.2-18.9 \%$ of the whole community, whereas abundant taxa comprises the 43.3-67.6\%. Therefore, although taxa that are abundant only consists of a few genera, these taxa often build most of the microbial community biomass (Fig. S5: Supplementary material). Moderately abundant taxa $(>0.1 \%$ and $<1 \%)$ sits between the abundant and rare, with a relative abundance of $19.6-37.7 \%$ in the samples studied.

\subsection{Functional characterization}

Coding sequences were functionally classified in order to infer potential functions. As expected, basic functions shared between all living beings are widely distributed among all samples, such as carbohydrate $(14.5 \%)$, amino acid (11.9\%), protein $(8.9 \%)$, DNA (5.9\%), RNA $(5.0 \%)$, and fatty acids and lipids $(3.1 \%)$ metabolisms; Other processes regarding cofactor, vitamins, and pigments $(10.7 \%)$, cell wall and capsule (4.2\%), respiration (3.9\%), and stress response $(3.8 \%)$ are also among the top functions for all samples. Stress response genes in higher abundance might reflect that the community is subject to ceaseless environmental pressures (Varin et al., 2012; Le et al., 2016). Fig. 3a shows the difference in function abundance between samples for every major process according to SUPER-FOCUS classification. Overall, samples appear to be similar among them, despite some functions with differential distribution among the samples, such as amino acid, fatty acids and lipids, central, secondary, and RNA metabolisms.

We inspect the function of the stress response genes present at the Archean Domes. Based on GO classification, we identify resistance genes related to $\mathrm{pH}$, alkaline, acidic, salt, dormancy, and endosporulation conditions. Alkaline and salt resistance genes were the most abundant, with a mean proportion of $56.5 \%$ and $31.5 \%$, respectively (Fig. S6: Supplementary material). This behavior is expected, since salt and $\mathrm{pH}$ fluctuate considerably between seasons, and might exert a selection pressure on the organisms thriving on this site.

Pfam protein groups were used to infer energy metabolisms and nutrient cycling within the mat samples. Based on normalized abundance, Wood-Ljungdahl pathway rules carbon metabolism among the mat, followed by the Calvin cycle. These results are consistent with other microbial mats previously described, and Wood-Ljungdahl dominance has been regarded as a result of energy limitation, since this mechanism of carbon fixation is inefficient compared to other pathways (Gutiérrez-Preciado et al., 2018; Wong, White, et al., 2018; Kurth et al., 2021). Anoxygenic photosynthesis genes dominate over those specific to oxygenic photosynthesis, while sulfur oxidation and nitrogen fixation are potentially the main processes for sulfur and nitrogen metabolisms. Dissimilatory sulfate reduction is portrayed as a process with low gene abundances, despite the highly abundant sulfate reducing bacteria previously described; as such, metabolism inference based on gene abundances should be taken cautiously. Further 
reconstruction of full pathways would provide more accuracy in the relative abundances.

\subsection{Community dynamics through time and seasonal comparison}

On account of the morphological changes of the pond in response to environmental perturbations, we conduct statistical analyses to evaluate if samples have higher resemblance to those collected in the same seasonal state. Chao, Shannon, and inverse Simpson indexes were calculated for each sample to evaluate alpha diversity, and no statistical significance was found between seasons (Wilcoxon Rank Sum test: Chao1 $p=0.4$, Shannon $p=1$, Inverse Simpson $p=0.8)$. Moreover, principal coordinates analysis (PCoA) and non-metric multidimensional scaling (NMDS) at the genus and order level showed no seasonal aggregation of samples (Fig. S7: Supplementary material). Finally, Canonical correspondance analysis (CCA) was performed with the environmental variables provided by the EMA meteorological station (Fig. S8: Supplementary material). From this analysis, roughly, 2017-2018 samples were driven by precipitation, whereas 2019 samples were driven by wind speed and humidity. This could be non-conclusive due to the low sample number. Nonetheless, two groups seem to have formed: one less closer to each other from samples of 2016 - 2018, and other more closely arranged which comprises the samples from 2019. This result is expected, as taxonomic profiles from the dry and rainy seasons of 2019 showed similar compositions (Fig. 2), particularly, the increase in the Archaea relative abundances.

Co-occurrance networks were built to inspect general properties at the phylum level (Table S7 and Fig S9: Supplementary material). Both seasons mainly show two clusters which might be associated to groups of highly interacting organisms or functional guilds with niche overlapping to some degree. During the rainy season, several phyla from both groups transition to build a third cluster. Hence, it is possible that phyla interact differently between themselves depending on environmental conditions. Network metrics have been used to evaluate resilience and resistance within microbial communities. For instance, our networks shows a positive edge of 49.017 and 48.77 during the dry and rainy seasons, respectively. A high positive/negative ratio in microbial networks, such as those found in these networks, has been interpreted to aid in community stability, by avoiding feedback loops in taxa with overlapping niches (Hernandez et al., 2021). Furthermore, modularity has been considered as a measure of community stability, diminishing the propagation of perturbations through the network (Hernandez et al., 2021). The Archean Domes microbial mats seem to change in modularity between the dry season (0.01) and rainy season (0.07) states; lower modularity during the dry season might reflect the exposure and vulnerability of the system relative to when the mats are wet. The small sample size might induce spurious correlations in the microbial networks, and further samplings for the following seasons will support this analysis.

Seasonal patterns in community composition are not straightforward to follow, and evaluating the community dynamics through the years might provide a plausible underlying explanation for this. Fig. 4a show the community composition changes through the years. As briefly stated previously, one of the most noticeable changes through the years was a rise of Archaea (from 1-4\% to 33\%) in the samples of 2019. Consequently, Bacteria reduced their abundance up to $\sim 65 \%$, a third less from previous years. The virus followed the same tendency as the archaea druing 2019, in a subtle rise of abundance (0.08$0.2 \%$ to $0.4 \%$ ). The Eukaryota had an apparent seasonal pattern in the first two years (2016-2018), continuing with a steady state in 2019. Since the increased abundance of Archaea was considerable, the dynamic between 2016-2018 is visually lost. Taking into account only the abundance shift between 2016-2018, all domains presented a possible seasonal pattern, where archaeas, eukaryotes and viruses rose proportionally in the rainy season compared to the dry one. To explore which organisms may drive these seasonal patterns, we examined phylum and genus proportion across time. Phyla with a prominent shift were Spirochaetes, Proteobacteria, Cyanobacteria, Cloroflexi, Bacteroidetes, and the Euryarchaeota. Euryarchaeota became one of the main abundant groups in the communities of 2019 
bioRxiv preprint doi: https://doi.org/10.1101/2021.11.18.469043; this version posted November 21, 2021. The copyright holder for this preprint (which was not certified by peer review) is the author/funder, who has granted bioRxiv a license to display the preprint in perpetuity. It is made available under aCC-BY-ND 4.0 International license.

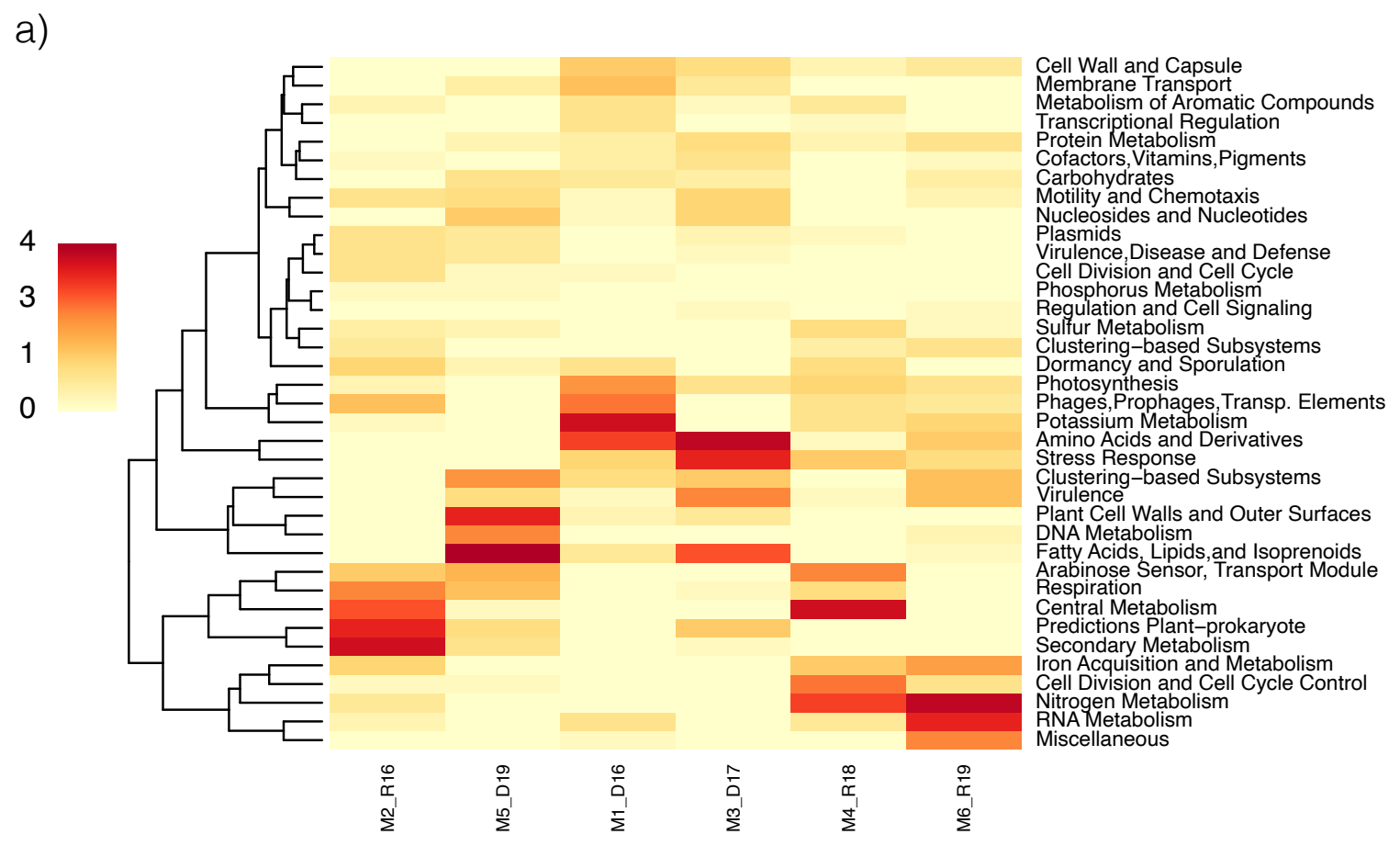

b)

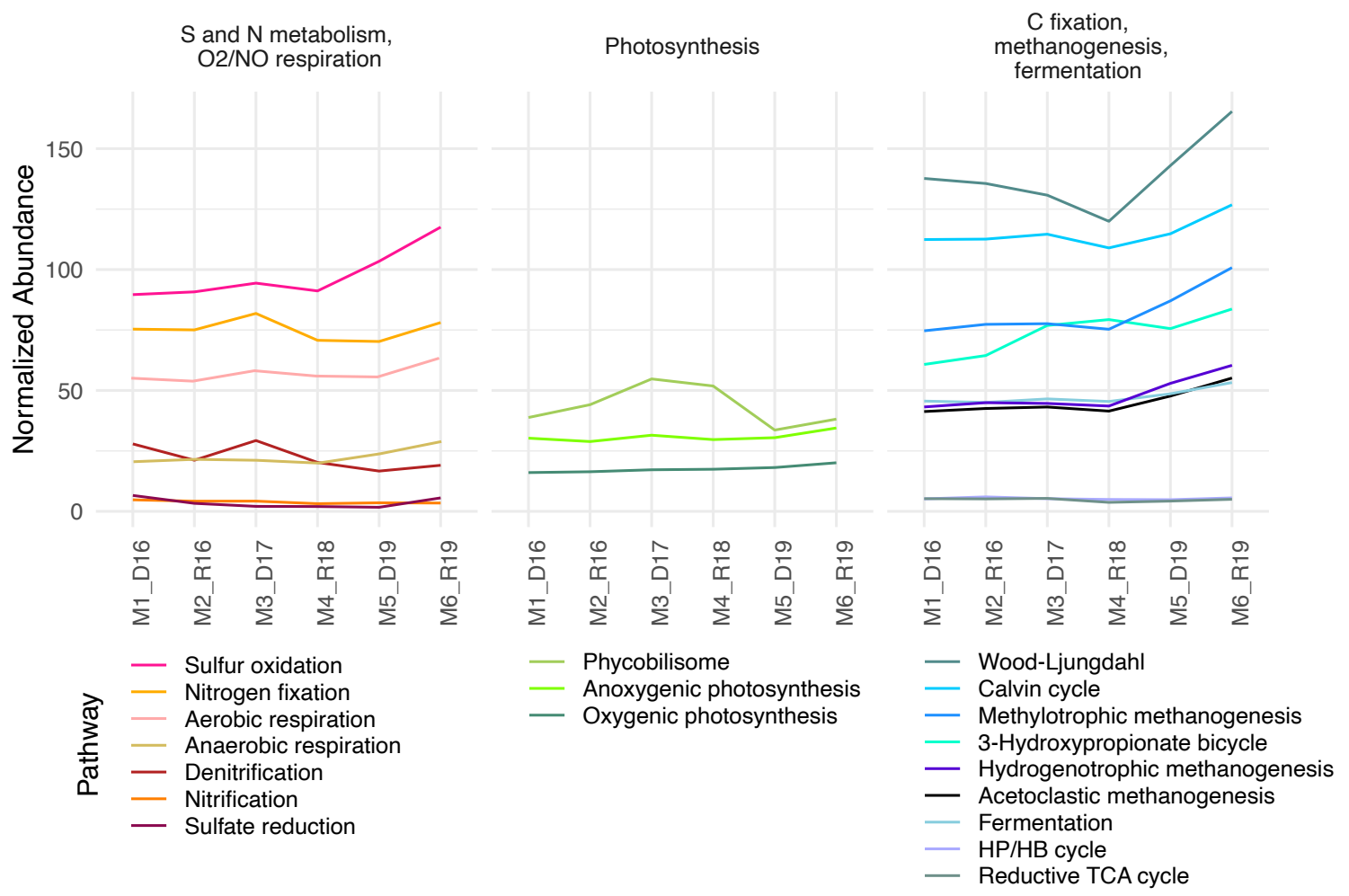

Fig. 3: Potential functional profile based on metagenomic inference. a) Heatmap of SUPER-FOCUS major functions, with color intensity reflecting differences in abundance between samples. b) Normalized abundance of selected pathways based on pathway-specific Pfam protein groups. $\mathrm{HP} / \mathrm{HB}=3-$ hydroxypropionate/4-hydroxybutyrate, TCA=tricarboxylic acid. 
(from 2\% to 28\%). In contrast, Cyanobacteria, Chloroflexi and Bacteroidetes showed a diminished abudnance during the same year. Spirochaetes had a rise in October 2016 to end in a constant frequency in the following samples.

At the genus level, the taxonomic replacement is even more noticeable (Fig. 4b). For each sampling, we could observe two main phenomena: i) some genera are present in every sample (core genera), while ii) most genera are new additions or become undetected between each sample. As a matter of fact, taxonomic replacement becomes increasingly complex with each new sample, which reflects how the community has changed since the first sampling in April 2016. We delve deeper into core dynamics in the following section. We were interested to evaluate which taxa are key in driving the community to new compositional states, based on the differential abundances between samples. Coupling UMAP, a nonlinear dimensionality reduction method, with HDBSCAN, Hierarchical Density-Based Spatial Clustering of Applications with Noise), we find groups that might be leading the community dynamics (Fig. 4c). First, the main cluster contains most of the genera, with the inclusion of all the abundant taxa (1734 genera in class 4). In contrast, four small groups with fewer genera in each one $(22,116,200$, and 182 genera in classes 0,1,2, and 3, respectively. Group composition is supplied as Supplementary material in a csv file). These groups are made up entirely of genera belonging to the rare biosphere, and shifts in their abundance seem to be major ecological drivers in the ecosystem. This result further support the relevance of the rare biosphere in microbial communities, as they could XXX (Jousset et al., 2017).

We assess if functional categories differentiate communities between seasons. Normalized abundances for general functions (system 1 level based on SUPER-FOCUS classification) showed that dry and rainy function abundance is essentially the same, with slight differences in abundance (Fig. 5a). This behavior is expected, as major functions, with fundamental roles in every microbe, are always present for the survival of the community. As described previously, most genes are associated to carbohydrate, amino acids, and protein, metabolisms as well as processes cofactors, vitamins, and pigments. Nevertheless, PCoA for these data with a Bray-Curtis measure do arrange them into seasonal groups, although ordination is sparse (Fig. 5b). Further sampling will support the predictability of this clustering method.

We modify a differential expression analysis to adapt it to our metagenomic using the classification defined by SUPER-FOCUS. Although none of the metabolic subsystems had a significant difference between seasons $(p>0.5)$, there were some processes that had a higher or lower abundance as seen by their fold change (Log2 Fold Change>abs[2.5], Fig. S10: Supplementary material). In the dry season, there were three slightly more abundant functions: the pentose phosphate pathway of plants, the alpha-acetolactate operon, and the biotin biosynthesis. From the pentose phosphate pathway, we had the glucose 6 phosphate dehydrogenase, the key enzyme of the Oxidative Pentose Phosphate Pathway (OPPP), which is related to the response of short- or long-term exposure to drought stress in plants (Landi et al., 2016). The alpha-acetolactate operon has been described as a component in the mixed acid fermentation, done by some bacteria such as Bacillus subtilis, to produce acetoin in the absence of nitrate (Härtig and Jahn, 2012); this could be associated to a shortage of nutrients in the dry season. Lastly, biotin biosynthesis is an important process, since biotin is a key cofactor in the fatty acids and amino acid metabolisms, as well as in the replenishment of the tricarboxylic acid cycle (Salaemae et al., 2016). For the rainy season, some functions with a higher fold change were: the acyl homoserine lactone (AHL) inducer, which is involved in primary quorum sensing signals by Gram-negative bacteria (Parsek et al., 1999); the phage carbon metabolism Auxiliary metabolic genes (AMGs), which consist of phage strategies for resource management during host infection (Thompson et al., 2011; Warwick-Dugdale et al., 2019); some archaeal hydrogenases, involved in carbon fixation (Hedderich, 2004); prenylated indole alkaloids production from actinomycetes, which have multiple 

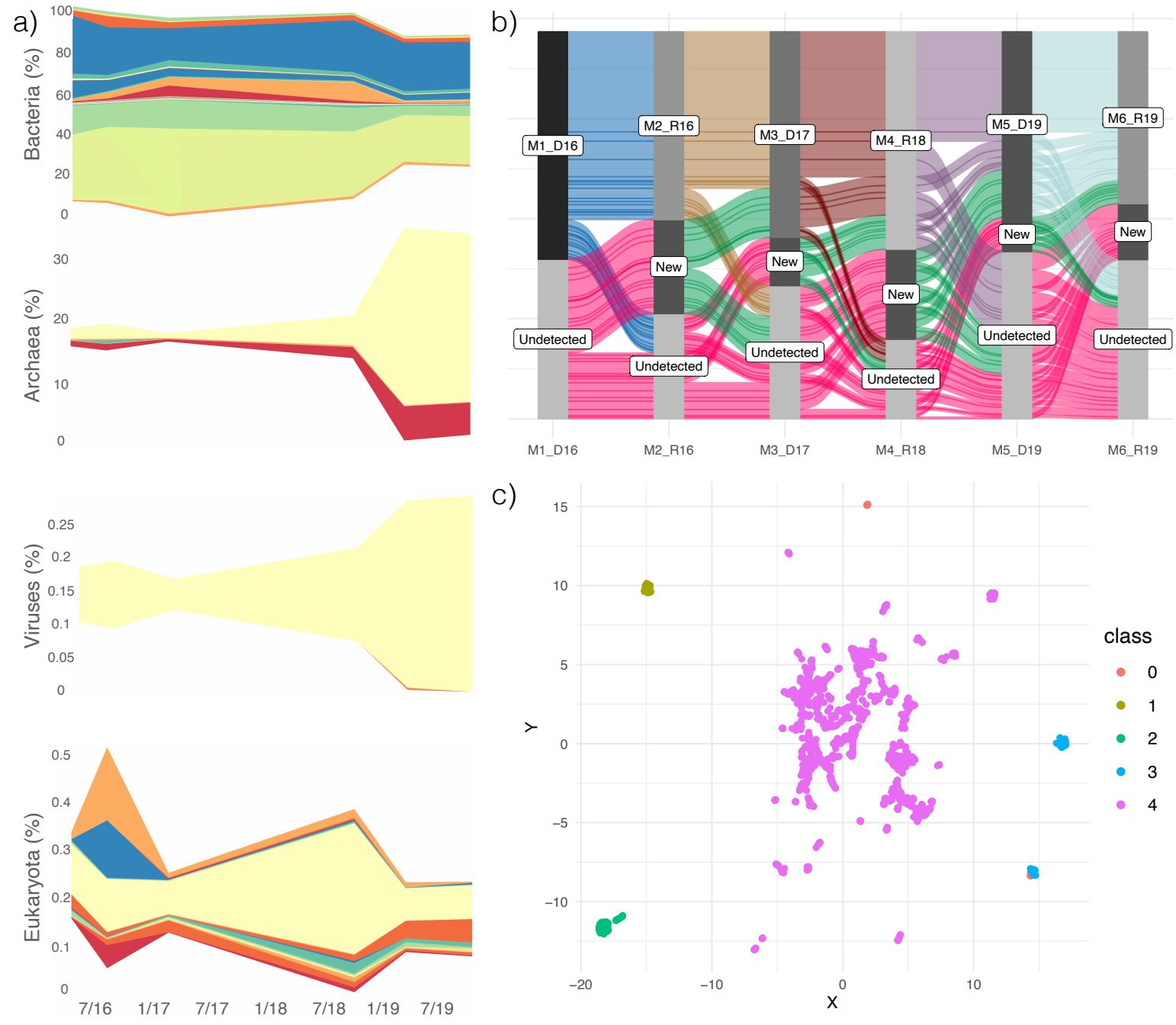

C)

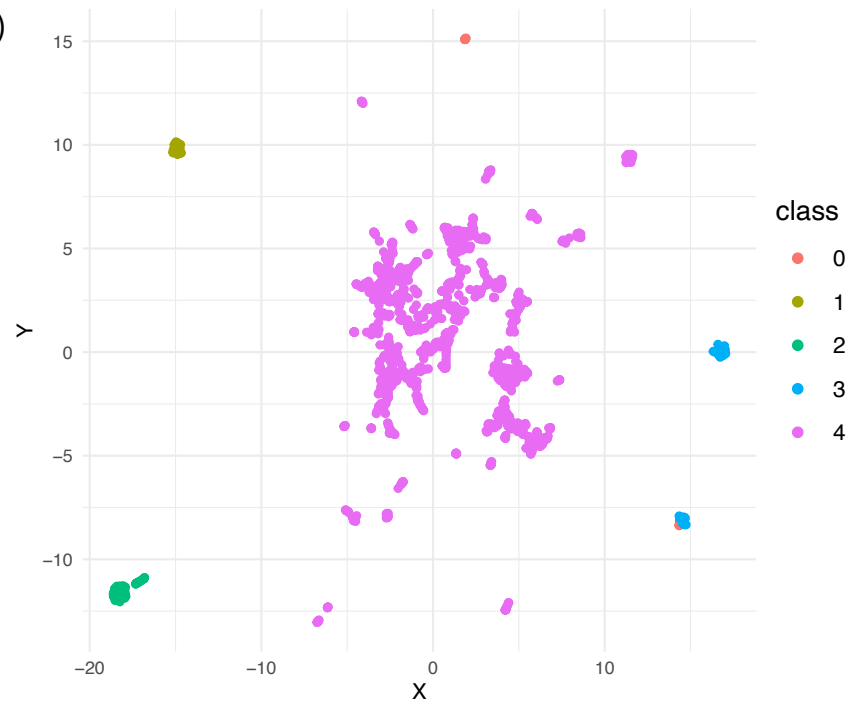

Fig. 4: Taxonomic replacement and community dynamics throughout the years. a) Changes in superkingdom abundances from 2016 to 2019. Colors within each graph depict phyla. b) Community dynamics at the genus level. Flows show genera that remain, appeared or disappeared from the system through the samples. c) UMAP dimension reduction and HDBSCAN clustering technique applied on the differences in genus abundance from each sample. 
a)

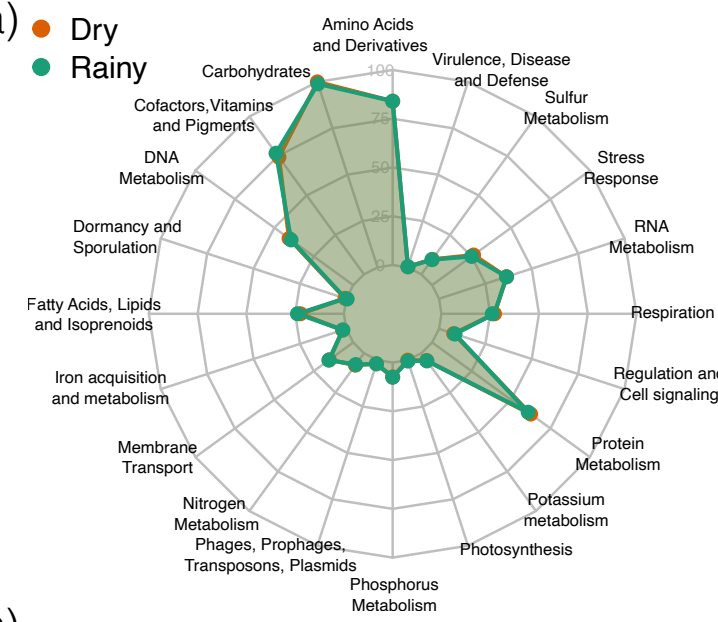

c)

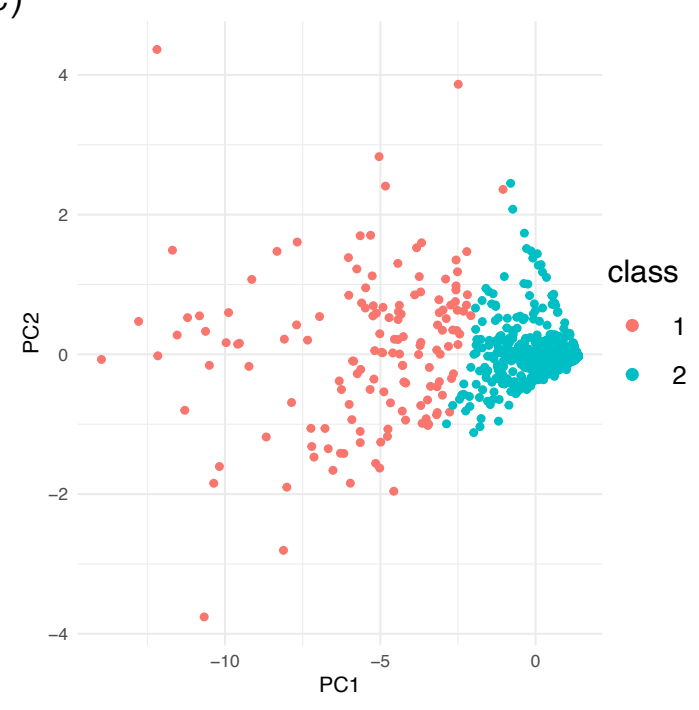

b)

\section{d)}
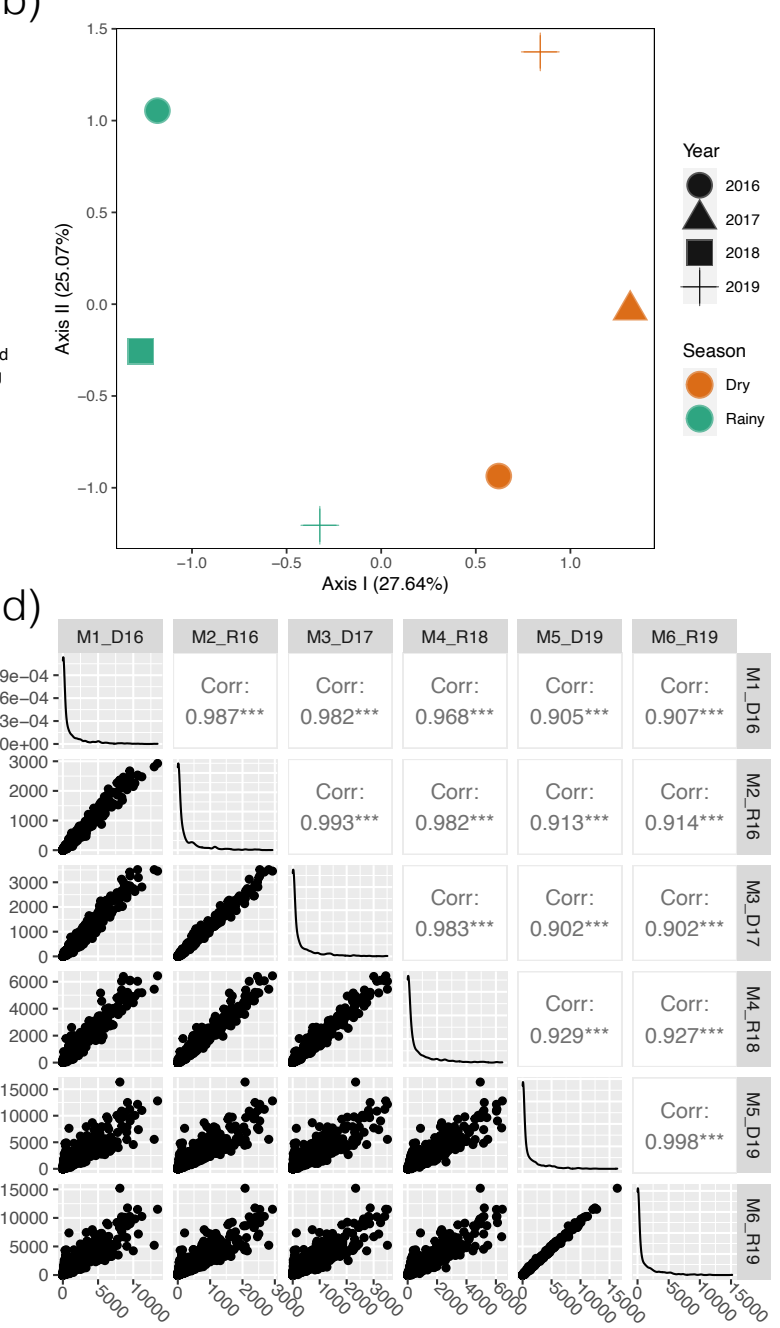

Fig. 5: Functional comparison between the years and functional changes throughout the years. a) Dry and Rainy season comparison based on Top SUPER-FOCUS processes. b) PCoA with Bray-Curtis measure, where samples are grouped, to some extent, by season. c) PCA analysis showing main groups of functions by k-means clustering. d) Correlations of function abundance between each sample, where each sample is more similar to the adjacent ones in time. 
biological functions such as antifungal and antibacterial activity (Netz and Opatz, 2015); and lastly, chlorophyll degradation related genes. Some of these functions could be directly associated with the presence of the green, cyanobacterial built, layer seen in the rainy seasons, such as in the phagecyanobacterial AMGs (Thompson et al., 2011), the quorum sensing for biofilm formation (Herrera and Echeverri, 2021), and the chlorophyll degradation.

Moreover, we were wondering how functions have changed over time and if there is a group of functions that leads global patterns in the community. According to k-means and hierarchical clustering, two main groups of functions were predicted. PCA analysis showed how these functions are projected, where high abundant functions are sparsely distributed in the plot, and most functions with low abundance functions were tightly clustered together (Fig. 5c). Each function's class is provided in the Supplementary material. Comparing function abundance across samples suggest that functions are more similar between adjacent samples (Fig. 5d). In consequence, the correlation cloud appears to be scattering when samples are more distant in time. For instance, sample M1_D16 showed higher correlation with sample M2_R16 than with the last sample from 2019 (M6_R19). This result further suggest that functions are changing between samples, and that cumulative changes in functions differ drastically from the initial function state. As previously stated, further sampling may reinforce this hypothesis.

\subsection{The core community}

Taxonomic composition and functions change through time to some extent, as described in the previous section. Still, there is a core community shared between all samples and seasons. The (global) core community consists of 250 genera out of the 2250 total genera across the samples, just about $\sim 11 \%$ of the total diversity found in the Archean Domes (Fig. 6a). These genera can be portrayed as microbes with high physiological plasticity, able to cope with both dry and rainy season environmental conditions (Pett-Ridge and Firestone, 2005). Seasonal cores were identified, that is, genera that only appeared in rainy or in dry season exclusively. Unlike the core community, seasonal cores were particularly small, with just 1 and 10 genera for dry and rainy seasons, accordingly. Every genus in the seasonal cores have a low abundance $(<0.01 \%)$, and belong to the rare biosphere during each season. The organisms found only in rainy samples comprise several Alphaproteobacteria (Croceicoccus, Shimia, Rhodoplanes, and Polymorphum), Gammaproteobacteria (Teredinibacter and Allochromatium), Bacteroidetes (Ohtaekwangia), Cyanobacteria (Geminocystis), one Euryarchaeota (Methanosalsum) and a novel genus of Planctomycetes (Candidatus Jettenia) previously described in an anammox bioreactor (Mardanov et al., 2019). Among the genera present only in rainy season, it is noticeable the presence of the phototrophs Allochromatium (purple sulfur bacteria), Rhodoplanes (photoheterotroph) and Geminocystis (Cyanobacteria) (Imhoff, 2014; Marcondes de Souza et al., 2014). Recently, a Croceicoccus species has been found to be capable to produce AHL (Huang et al., 2015), which could be consistent with the slight increase in the AHL inducer genes during the rainy season. Teredinibacter have nitrogen fixation capabilities (Distel et al., 2002), while Methanosalum is a methylotrophic methanogen (Oren, 2014), which might aid in nutrient cycling during the rainy season. In contrast, the dry season core only contained the Maledivibacter genus, a member of the Clostridiales, Firmicutes. This genus produces hydrogen sulfide and ammonia under obligately halophilic conditions (Li, Zeng, et al., 2016). In fact, all the genera found in the seasonal cores are halophilic to some extent.

We further analyzed the taxonomical structure and functions of the global core community. The core community consists of 250 genera, where most of them belong to the Proteobacteria (102), Bacteroidetes (43), Firmicutes (28), Euryarchaeota (12), Actinobacteria (11), and Cyanobacteria (10) (Fig. S11: Supplementary material). Although these genera appear in every sample, their relative abundances fluctuate drastically between samples (Fig. S12: Supplementary material). For instance, 
bioRxiv preprint doi: https://doi.org/10.1101/2021.11.18.469043; this version posted November 21, 2021. The copyright holder for this preprint (which was not certified by peer review) is the author/funder, who has granted bioRxiv a license to display the preprint in perpetuity. It is made available under aCC-BY-ND 4.0 International license.

a)

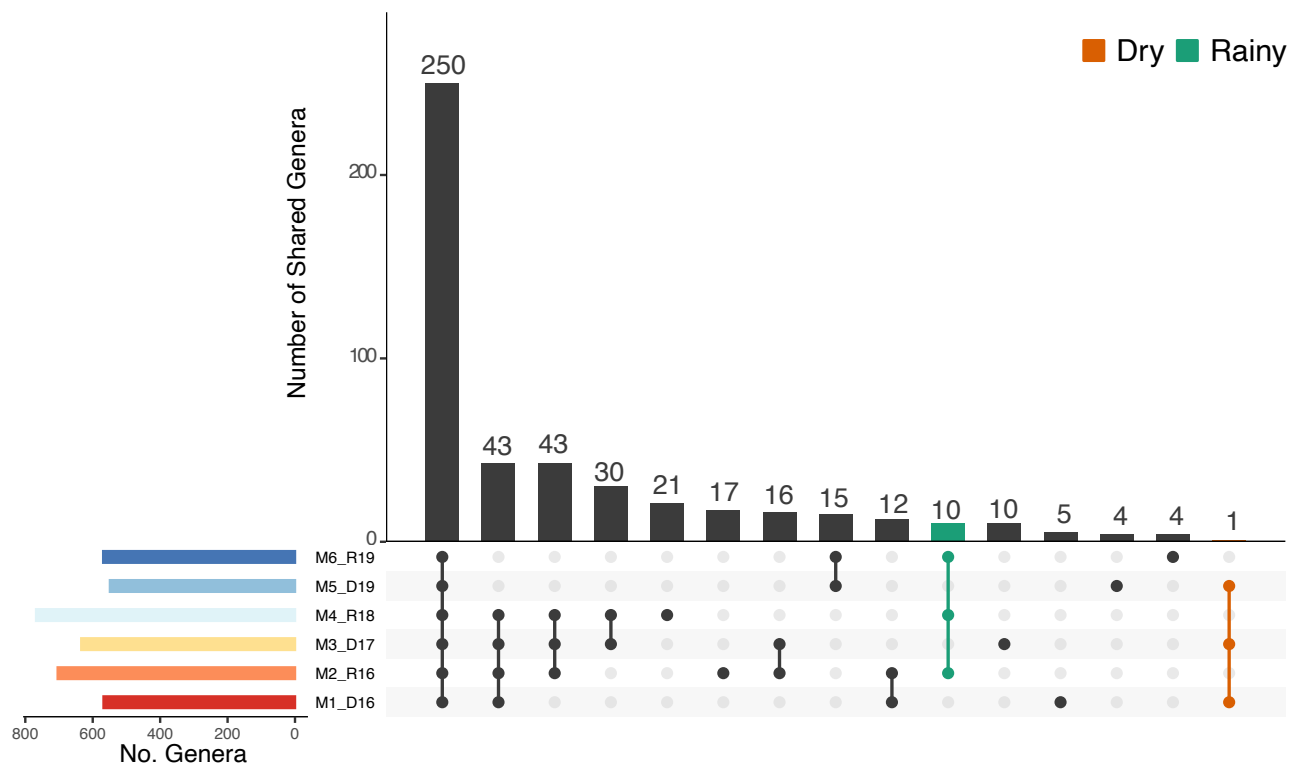

b)
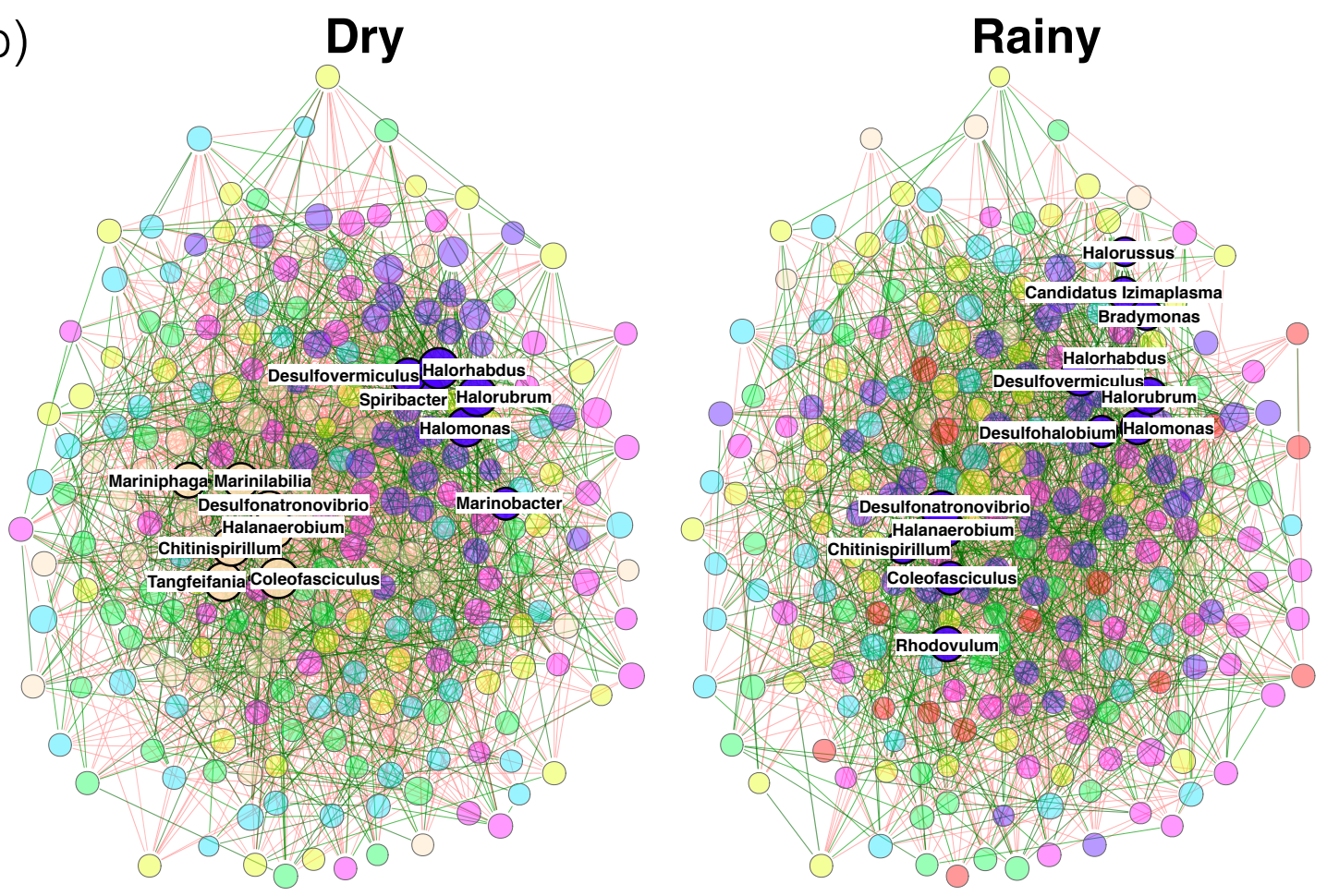

Fig. 6: The core community at the Archean Domes microbial system. a) Upset plot showing the number of shared genera between different sample intersections. Global core showed 250 genera, while rainy core and dry core showed 10 and 1 genera, respectively. b) Co-occurrence networks for core genera during the dry and rainy seasons, where color indicates different clusters. Green and red edges represent positive and negative relationships, respectively. Hub taxa are shown with labels 
Coleofasciculus transitioned from one of the genera with the highest abundance $(10.2 \%)$ in 2017 to belong to the rare biosphere $(0.06 \%)$ during the dry season of 2019. Most of the genera belonging to the core belong to the rare biosphere, although all the abundant genera belong to the core as well. Core functions relative abundances, on the other hand, appear highly conserved between samples (Fig. S11: Supplementary material), with processes such as carbohydrate, amino acid, protein, RNA, and DNA metabolisms being the most abundant ones. This result is consistent with the abundances of functions for the whole microbial system. PCoA ordination method suggest a seasonal pattern of functions, as the dry season samples of 2019 and 2016 were grouped in one cluster, while the rainy season samples of 2016 and 2018 were close to each other in another group. the dry season sample of 2017 and the rainy season sample from 2019 does not cluster to any of the aforementioned groups, and more samples will determine if these groups do preserve a seasonal pattern or not.

Core co-occurrence networks at the genus level also provide insights into the global core dynamics for both the dry and rainy seasons (Fig. 6). To begin with, there are 7 shared clusters of genera in both, dry and rainy seasons. Consistent with the networks built at the phylum level, the rainy season network for the 250 core genera displayed the addition of a new cluster that was not previously present in the dry season network. Additionally, many of the present genera relocate to different clusters between the dry and rainy seasons. This behavior could reflect how the core taxa differentially interact with each other in response to the environmental pressure. Even though these taxa are present in the whole community, regardless of the season, it is natural to infer that interactions within this core community are the ones that changes through the seasons. For both networks, global metrics were calculated, and once again, modularity and positive/negative ratio show consistency with the wholecommunity phylum networks (Table S7: Supplementary material); dry and rainy seasons displayed relatively high modularity values ( 0.17 and 0.22 , respectively), and the slightly lower value during the dry season could reflect a drop in community stability during this state. Positive edges in both networks account for the $\sim 41 \%$, which result in high positive/negative ratios that further suggest a resistant and resilient community (Hernandez et al., 2021). Finally, hub taxa were predicted for each network, and among them, Coleofasciculus, Chitinispirillum, Desulfonatronovibrio, Desulfovermiculus, Halanaerobium, Halomonas, Halorhabdus, and Halorubrum are shared hubs between the seasons. Two hub groups appear during the dry season, whereas during the rainy season, every hub genus belong to the same cluster. It seems that some hub taxa (including Desulfonatronovibrio, Coleofasciculus, Halanaerobium, and Chitinispirillum) are also involved in the differential interactions between seasons. Given that sample size is small, detailed interaction analysis should be taken with caution. Thus, we retain ourselves to just an exploratory, non-conclusive, global analysis of these networks.

\section{Discussion}

Our metagenomic profiling from 2016 to 2019 at the Archean Domes aided us in the understanding of how microbial communities at this site are able to cope to environmental pressures during the dry and rainy seasons. Extended drought during roughly 9 months each year could be classified as a press disturbance, whereas daily temperature shifts amidst the desert could be interpreted as a pulse perturbation. Hence, the Archean Domes could be regarded as a multi-perturbation system.

Ecological resistance has been classically associated with the species/genera richness, where an increase or decrease in biodiversity could point to a decrease in compositional stability (Pennekamp et al., 2018). Nonetheless, there were none statistically significant differences for alpha diversity between the communities of the dry and rainy seasons. Moreover, we could infer that the community's composition is heavily affected by each seasonal shift, pointing towards a sensitive, non-resistant, microbial community (Baho et al., 2012). Although community composition is constantly subject to 
taxonomic replacement, functions are mostly conserved, even though adjacent samples have shown more similarity in terms of function. Since functions are mostly preserved throughout the seasons, the highly diverse community might harbor a high degree of functionally redundant taxa (Allison and Martiny, 2008). This grants the community a robust capability to withstand taxonomic replacement, the product of a non-resistant community in terms of composition. Co-occurrence networks for the global (phylum level) and core (genus level) microbial networks show consistent results, as modularity and positive/negative ratio points towards a functionally stable community; in this sense, modules in these networks might reliably represent functional guilds or niche overlapping (Röttjers and Faust, 2018; Hernandez et al., 2021).

On the other hand, ecological resilience is not straightforward to assess in this system, as press disturbances are continuous and seasonal. Rather, inferences on ecological resilience could be evaluated under the assumption of many stable states in which a community may thrive. PCoA plots could be visualized as stability landscapes, where each snapshot of the community's composition/function could be envisioned as a ball and where the different alternative stable states represent basins in the landscape. If resistance and resilience is high, a disturbance would not modify the current stable state of the community. On the contrary, if overall stability is low, and the disturbance powerful enough, the community will leave its current stable state to fall into an alternative stable state (Botton et al., 2006; Shade et al., 2012). PCoA plot for taxonomic composition (Fig. S7: Supplementary material), could be interpreted as the community transitioning towards different compositional states from 2016 until 2018, but in the 2019 samples the community remained in the same compositional state. Looking at the PCoA plot for functions (Fig. 5) we could see that seasonal "valleys" of alternative equilibrium are formed, whereas PCoA for the core functions, the community do return to the same seasonal stable state despite the press disturbance.

Community stability in this site has different components that contribute to the whole microbial resistance and resilience, at least functionally speaking. First, at the individual level, we found abundant genes related to salt and alkaline stress response which could confer physiological plasticity to the global core community, as these genera thrived despite the seasonal conditions. Mixotrophy is well represented in microbial communities and could further explain the individual functional plasticity between seasons (Eiler, 2006). At the population level, disturbances are well known to foster diversification, as these perturbations bring the community under selection pressures (Rainey and Travisano, 1998; Galand et al., 2016). The high diversity found in this pond might be the outcome of the multiple selection pressures acting on the microbial populations, providing an evolutionary adaptation; diversity overall at the community level promote functional resistance, since functional redundancy is expected in a genetically diverse community (Shade et al., 2012). For example, the Archean Domes microbial mats possess several carbon and energy metabolisms which could enhance the robustness of primary production and nutrient cycling. Finally, differential growth rates among the community members influence the overall composition, yet, we have seen that the microbial rare biosphere might play a key role in driving the community to new stable compositional states. Indeed, the rare biosphere drastically influence the taxonomic replacement in other systems (Jousset et al., 2017; Pascoal et al., 2021).

As stated previously, the Archean Domes microbial system is constantly subject to environmental stress, which could be arguably compared to those experienced by the Shark Bay microbial mats, a recognized terrestrial analog (Wong, White, et al., 2018; Campbell et al., 2020). Therefore, the Archean Domes site is potentially a promising analog for early Earth, and (plausibly) early Mars, just as other potential analogs found in the Cuatro Ciénegas Basin (López-Lozano et al., 2012; MorenoLetelier et al., 2012; Souza et al., 2012). That being said, what can we learn of early life from these extant microbial communities? 
Local and planetary disturbances throughout Earth's history can be interpreted as environmental pulses or presses that perturbed the biosphere. Within this framework, microbial mats were biological structures that survived the onset of these threatening phenomena. Communities were probably compositionally sensitive, as shown by the microbial mats in this study and other microbial communities studied elsewhere (Allison and Martiny, 2008; Shade et al., 2012). While lineage extinction is expected as an effect of disturbances (Konhauser et al., 2015; Hodgskiss et al., 2019), multiple diversification events have been associated to post-disturbance episodes, such as genetic innovations driven by ocean-atmosphere oxygenation and changes in ocean chemistry (David and Alm, 2010; Chen, Sun, et al., 2020), or new clade emergence after major glaciation events (Chumakov, 2010). Therefore, Low compositionally resistant communities coupled with high mutation rates and further diversification within microbial mats could greatly influence the ceaseless search for alternative stable states in the stability landscapes. As major disturbances could completely modify the stability landscape (Shade et al., 2012), original compositional states could be never reached again, once the community is disturbed. Hence, it is plausible that modern composition of microbial mats (at least at the genus level) is substantially different from those during the Archean or Proterozoic Earth, and records of past compositional states might be unachievable.

As opposed to the continuous taxonomic replacement experienced in these systems, functional capability must have been a conservative feature for microbial mats throughout geologic time, as both resistance and resilience in functions were found for this analog site. Indeed, the fossil record show that modern metabolic capabilities could be traced back to past microbial mats and stromatolites (Buick, 1992; Bosak et al., 2009; Schopf, 2011; Lepot, 2020). This functional processes might be highly conserved across the community's core, where functional redundancy is expected. Most modern microbial mat development is highly reliant on phototrophic cyanobacteria (Noffke, 2010; PrietoBarajas et al., 2018), which lead us to wonder if microbial communities behaved similarly prior to the emergence of oxygenic photosynthesis. In this study, we find functional guilds that are stable to environmental perturbations, in which oxygenic photosynthesis is part of a local electron transfer circuit that includes energy and carbon metabolisms (Jelen et al., 2016). Closed electron transport circuits existed prior to the emergence of oxygenic photosynthesis, as depicted in Moore et al. (2017), where aerobic metabolisms emerged at a later stage in biological evolution. In this sense, microbial mats without oxygenic photosynthesis could rely on other metabolic processes to cycle nutrients and energy and become highly stable structures to functional changes. Future studies on modern microbial mats in hydrothermal vents (Rassa et al., 2009; Miranda et al., 2016) and phototrophic, anoxygenic sites (Visscher et al., 2020) would provide insights into this hypothesis.

Reconstructing past microbial ecologies, including their ecological stability, might provide valuable insights into the coevolution of the biosphere-geosphere. This knowledge has the potential to be applied to forecast microbial response under contemporary disturbances of global climate change, (Reinold et al., 2019), as well as potential modelling for microbial systems beyond Earth's limits, where perturbations might be even more harsh than those experienced by terrestrial life.

\section{Financial Disclosure Statement}

This research was supported by $\mathrm{PhD}$ scholarship 970341 granted by Consejo Nacional de Ciencia y Tecnología (CONACyT) and DGAPA/UNAM-PAPIIT Project IG200319.

\section{Competing interests}

The authors declare no competing financial interests. 


\section{References}

Allison, Steven D. and Jennifer B. H. Martiny (2008). "Resistance, resilience, and redundancy in microbial communities". In: Proceedings of the National Academy of Sciences 105.Supplement 1, pp. 11512-11519. ISSN: 0027-8424. DOI: 10 .1073/PNAS .0801925105. URL: https : //www . pnas . org/content/105/Supplement_1/11512\%20https://www . pnas .org/content/105/Supplement_ $1 / 11512$.abstract.

Altschul, Stephen F., Warren Gish, Webb Miller, Eugene W. Myers, and David J. Lipman (1990). "Basic local alignment search tool". In: Journal of Molecular Biology 215.3, pp. 403-410. ISSN: 0022-2836. DOI: 10.1016/S0022-2836(05)80360-2.

Arnscheidt, Constantin W and Daniel H Rothman (2020). "Routes to global glaciation". In: Proceedings of the Royal Society A 476.2239, p. 20200303. ISSN: 1364-5021. DOI: 10.1098/RSPA. 2020.0303. URL: https://royalsocietypublishing.org/doi/abs/10.1098/rspa. 2020.0303.

Baho, Didier L., Hannes Peter, and Lars J. Tranvik (2012). "Resistance and resilience of microbial communities - temporal and spatial insurance against perturbations". In: Environmental Microbiology 14.9, pp. 2283-2292. ISSN: 1462-2920. DOI: 10.1111/J.1462-2920.2012.02754.X. URL: https : //onlinelibrary . wiley. com/doi/full/10.1111/j.1462-2920.2012.02754 . x\%20https : // onlinelibrary . wiley. com/doi /abs / 10.1111/j . 1462-2920.2012.02754 . x\%20https : //sfamjournals.onlinelibrary.wiley.com/doi/10.1111/j.1462-2920.2012.02754.x.

Bandla, Aditya, Shruti Pavagadhi, Ashwin Sridhar Sudarshan, Miko Chin Hong Poh, and Sanjay Swarup (2020). "910 metagenome-assembled genomes from the phytobiomes of three urban-farmed leafy Asian greens". In: Scientific Data 2020 7:1 7.1, pp. 1-7. ISSN: 2052-4463. DOI: $10.1038 /$ s41597-020-00617-9. URL: https://www .nature.com/articles/s41597-020-00617-9.

Bateman, Alex et al. (2021). "UniProt: the universal protein knowledgebase in 2021". In: Nucleic Acids Research 49.D1. ISSN: 0305-1048. DOI: 10.1093/nar/gkaa1100.

Bender, E. A., T. J. Case, and M. E. Gilpin (1984). "Perturbation Experiments in Community Ecology: Theory and Practice". In: Ecology 65.1, pp. 1-13. ISSN: 1939-9170. DOI: 10.2307/1939452. URL: https://onlinelibrary.wiley.com/doi/full/10.2307/1939452\%20https://onlinelibrary. wiley.com/doi/abs/10.2307/1939452\%20https ://esajournals . onlinelibrary.wiley.com/ doi/10.2307/1939452.

Berga, Mercè, Yinghua Zha, Anna J. Székely, and Silke Langenheder (2017). "Functional and compositional stability of bacterial metacommunities in response to salinity changes". In: Frontiers in Microbiology 8.JUN, p. 948. ISSN: 1664302X. DOI: 10.3389/FMICB. 2017.00948/BIBTEX.

Bischl, Bernd, Michel Lang, Jakob Bossek, Daniel Horn, Jakob Richter, and Dirk Surmann (2017). BBmisc: Miscellaneous Helper Functions for B. Bischl. URL: https : / CRAN. R-project.org/ package $=$ BBmisc .

Blighe, Kevin, Sharmila Rana, and Myles Lewis (2021). EnhancedVolcano: Publication-ready volcano plots with enhanced colouring and labeling. URL: https : //github.com/kevinblighe/ EnhancedVolcano.

Bolger, Anthony M., Marc Lohse, and Bjoern Usadel (2014). "Trimmomatic: a flexible trimmer for Illumina sequence data". In: Bioinformatics 30.15, pp. 2114-2120. ISSN: 1367-4803. DOI: 10.1093/ BIOINFORMATICS/BTU170. URL: https ://academic . oup.com/bioinformatics/article/30/15/ $2114 / 2390096$.

Bosak, Tanja, Biqing Liang, Sub Sim Min, and Alexander P. Petroff (2009). "Morphological record of oxygenic photosynthesis in conical stromatolites". In: Proceedings of the National Academy of Sciences 106.27, pp. 10939-10943. ISSN: 0027-8424. DOI: 10.1073/PNAS.0900885106. URL: https: 
//www . pnas . org/content/106/27/10939\%20https ://www . pnas . org/content/106/27/10939. abstract.

Botton, S., M. Van Heusden, J. R. Parsons, H. Smidt, and N. Van Straalen (2006). "Resilience of Microbial Systems Towards Disturbances". In: http://dx.doi.org/10.1080/10408410600709933 32.2, pp. 101-112. ISSN: 1040841X. DOI: 10 . $1080 / 10408410600709933$. URL: https : / / www . tandfonline.com/doi/abs/10.1080/10408410600709933.

Brenes-Guillén, L., D. Vidaurre-Barahona, M. Mora-López, and L. Uribe-Lorío (2021). " Draft Genome Sequences of Two Cyanobacteria Leptolyngbya spp. Isolated from Microbial Mats in Miravalles Thermal Spring, Costa Rica ". In: Microbiology Resource Announcements 10.41. ISSN: 2576098X. DOI: 10 . 1128 / MRA . 00553-21 / ASSET / EE48F170 - BE82 - 4739 - 9449 - 901C375640F3 / ASSETS / IMAGES/LARGE/MRA .00553-21-F001. JPG. URL: https://journals .asm.org/doi/abs/10.1128/ MRA. 00553-21.

Buchfink, Benjamin, Chao Xie, and Daniel H Huson (2014). "Fast and sensitive protein alignment using DIAMOND". In: Nature Methods 2014 12:1 12.1, pp. 59-60. ISSN: 1548-7105. DOI: 10.1038/ nmeth.3176. URL: https://www . nature.com/articles/nmeth. 3176.

Buick, Roger (1992). "The antiquity of oxygenic photosynthesis: evidence from stromatolites in sulphate-deficient Archaean lakes". In: Science (New York, N.Y.) 255.5040, pp. 74-77. ISSN: 00368075. DOI: 10.1126/SCIENCE.11536492. URL: https://pubmed.ncbi.nlm.nih.gov/11536492/.

Bushnell, B (2020). BBmap. URL: https://sourceforge.net/projects/bbmap/.

Campbell, Matthew A., Kliti Grice, Pieter T. Visscher, Therese Morris, Hon Lun Wong, Richard Allen White, Brendan P. Burns, and Marco J.L. Coolen (2020). "Functional Gene Expression in Shark Bay Hypersaline Microbial Mats: Adaptive Responses". In: Frontiers in Microbiology 11, p. 2741. ISSN: 1664302X. DOI: 10.3389/FMICB. 2020.560336/BIBTEX.

Cardoso, Daniela Clara, Mariana Silvia Cretoiu, Lucas J. Stal, and Henk Bolhuis (2019). "Seasonal development of a coastal microbial mat". In: Scientific Reports 2019 9:1 9.1, pp. 1-14. ISSN: 20452322. DOI: $10.1038 / \mathrm{s} 41598-019-45490-8$. URL: https ://www . nature.com/articles/s41598019-45490-8.

Chen, Song Can, Guo Xin Sun, Yu Yan, Konstantinos T. Konstantinidis, Si Yu Zhang, Ye Deng, Xiao Min Li, Hui Ling Cui, Florin Musat, Denny Popp, Barry P. Rosen, and Yong Guan Zhu (2020). "The Great Oxidation Event expanded the genetic repertoire of arsenic metabolism and cycling". In: Proceedings of the National Academy of Sciences of the United States of America 117.19, pp. 10414-10421. ISSN: 10916490. DOI: 10.1073/PNAS . 2001063117/- /DCSUPPLEMENTAL. URL: https://www.pnas.org/content/117/19/10414\%20https://www.pnas.org/content/117/ 19/10414. abstract.

Chen, Wen, Joshua Simpson, and C Andre Levesque (2018). RAM: R for Amplicon-Sequencing-Based Microbial-Ecology. URL: https://CRAN.R-project.org/package=RAM.

Chumakov, N. M. (2010). "Precambrian glaciations and associated biospheric events". In: Stratigraphy and Geological Correlation 2010 18:5 18.5, pp. 467-479. ISSN: 1555-6263. DOI: $10.1134 /$ S0869593810050011. URL: https://link.springer.com/article/10.1134/S0869593810050011.

Davatzes, Alexandra Krull, Steven Goderis, and Bruce M. Simonson (2019). "Archean Asteroid Impacts on Earth: Stratigraphic and Isotopic Age Correlations and Environmental Consequences". In: Earth's Oldest Rocks, pp. 169-185. DOI: 10.1016/B978-0-444-63901-1.00008-3.

David, Lawrence A. and Eric J. Alm (2010). "Rapid evolutionary innovation during an Archaean genetic expansion". In: Nature 2010 469:7328 469.7328, pp. 93-96. ISSN: 1476-4687. DOI: 10.1038/ nature09649. URL: https://www.nature.com/articles/nature09649.

Distel, Daniel L, Wendy Morrill, Noelle MacLaren-Toussaint, Dianna Franks, and John Waterbury (2002). "Teredinibacter turnerae gen. nov., sp. nov., a dinitrogen-fixing, cellulolytic, endosym- 
biotic gamma-proteobacterium isolated from the gills of wood-boring molluscs (Bivalvia: Teredinidae)." In: International Journal of Systematic and Evolutionary Microbiology 52.6, pp. 22612269. ISSN: 1466-5026. DOI: 10 . 1099/00207713-52-6-2261/CITE / REFWORKS. URL: https : //www.microbiologyresearch.org/content/journal/ijsem/10.1099/00207713-52-6-2261.

Eddy, Sean R. (2011). "Accelerated Profile HMM Searches". In: PLOS Computational Biology 7.10, e1002195. ISSN: 1553-7358. DOI: 10 . 1371 / JOURNAL . PCBI . 1002195. URL: https : / / journals . plos.org/ploscompbiol/article?id=10.1371/journal . pcbi. 1002195.

Eiler, Alexander (2006). "Evidence for the Ubiquity of Mixotrophic Bacteria in the Upper Ocean: Implications and Consequences". In: Applied and Environmental Microbiology 72.12, p. 7431. ISSN: 00992240. DOI: 10 .1128/AEM . 01559-06. URL: /pmc/articles/PMC1694265/\%20https : //www . ncbi.nlm.nih.gov/pmc/articles/PMC1694265/.

Erdmann, Weronika, Hanna Kmita, Jakub Z. Kosicki, and Lukasz Kaczmarek (2021). "How the Geomagnetic Field Influences Life on Earth - An Integrated Approach to Geomagnetobiology". In: Origins of Life and Evolution of Biospheres 2021 51:3 51.3, pp. 231-257. ISSN: 1573-0875. DOI: 10.1007/S11084-021-09612-5. URL: https://link. springer.com/article/10.1007/s11084021-09612-5.

Espinosa-Asuar, Laura, Camila Monroy, David Madrigal-Trejo, Marisol Navarro-Miranda, Jazmín Sánchez-Pérez, Jhoseline Muñoz, Juan Diego Villar, Julián Cifuentes, Maria Kalambokidis, Diego A. Esquivel-Hernández, Mariette Viladomat, Ana Elena Escalante-Hernández, Patricia Velez, Mario Figueroa, Santiago Ramírez Barahona, Jaime Gasca-Pineda, Luis E. Eguiarte, and Valeria Souza (2021). "Ecological relevance of abundant and rare taxa in a highly-diverse elastic hypersaline microbial mat, using a small-scale sampling". In: bioRxiv, p. 2021.03.04.433984. DOI: 10.1101/2021. 03.04 . 433984. URL: https : / /www . biorxiv . org/content/10.1101/2021.03.04.433984v2\% 20https://www.biorxiv.org/content/10.1101/2021.03.04.433984v2.abstract.

Galand, Pierre E., Sabrina Lucas, Sonja K. Fagervold, Erwan Peru, Audrey M. Pruski, Gilles Vétion, Christine Dupuy, and Katell Guizien (2016). "Disturbance increases microbial community diversity and production in marine sediments". In: Frontiers in Microbiology 7.DEC, p. 1950. ISSN: 1664302X. DOI: $10.3389 /$ FMICB. 2016.01950/BIBTEX.

García-García, Natalia, Javier Tamames, Alexandra M. Linz, Carlos Pedrós-Alió, and Fernando Puente-Sánchez (2019). "Microdiversity ensures the maintenance of functional microbial communities under changing environmental conditions". In: The ISME Journal 2019 13:12 13.12, pp. 29692983. ISSN: 1751-7370. DOI: $10.1038 /$ s41396-019-0487-8. URL: https : //www . nature . com/ articles/s41396-019-0487-8.

Gumsley, Ashley, Joaen Stamsnijder, Emilie Larsson, Ulf Söderlund, Tomas Naeraa, Michiel De Kock, Anna Sałacińska, Aleksandra Gaweda, Fabien Humbert, and Richard Ernst (2020). "Neoarchean large igneous provinces on the Kaapvaal Craton in southern Africa re-define the formation of the Ventersdorp Supergroup and its temporal equivalents". In: GSA Bulletin 132.9-10, pp. 1829-1844. ISSN: 0016-7606. DOI: 10.1130/B35237.1. URL: https://doi.org/10.1130/B35237.1; .

Gumsley, Ashley P., Kevin R. Chamberlain, Wouter Bleeker, Ulf Söderlund, Michiel O. De Kock, Emilie R. Larsson, and Andrey Bekker (2017). "Timing and tempo of the great oxidation event". In: Proceedings of the National Academy of Sciences of the United States of America 114.8, pp. 18111816. ISSN: 10916490. DOI: 10.1073/PNAS . 1608824114/-/DCSUPPLEMENTAL. URL: https://www . pnas.org/content/114/8/1811\%20https://www . pnas.org/content/114/8/1811 . abstract.

Gutiérrez-Preciado, Ana, Aurélien Saghaï, David Moreira, Yvan Zivanovic, Philippe Deschamps, and Purificación López-García (2018). "Functional shifts in microbial mats recapitulate early Earth metabolic transitions". In: Nature Ecology 83 Evolution 2018 2:11 2.11, pp. 1700-1708. ISSN: 2397- 
334X. DOI: 10.1038/s41559-018-0683-3. URL: https://www . nature.com/articles/s41559018-0683-3.

Härtig, Elisabeth and Dieter Jahn (2012). "Regulation of the Anaerobic Metabolism in Bacillus subtilis". In: Advances in Microbial Physiology 61, pp. 195-216. ISSN: 0065-2911. DOI: 10.1016/B9780-12-394423-8.00005-6.

Hedderich, Reiner (2004). "Energy-converting [NiFe] hydrogenases from archaea and extremophiles: ancestors of complex I". In: Journal of bioenergetics and biomembranes 36.1, pp. 65-75. ISSN: 0145479X. DOI: 10.1023/B: JOBB.0000019599.43969.33. URL: https://pubmed.ncbi.nlm.nih.gov/ $15168611 /$.

Hernandez, Damian J., Aaron S. David, Eric S. Menges, Christopher A. Searcy, and Michelle E. Afkhami (2021). "Environmental stress destabilizes microbial networks". In: The ISME Journal 2021 15:6 15.6, pp. 1722-1734. ISSN: 1751-7370. DOI: 10 . 1038/S41396-020-00882-X. URL: https://www-nature-com.pbidi . unam.mx:2443/articles/s41396-020-00882-x.

Herrera, Natalia and Fernando Echeverri (2021). "Evidence of Quorum Sensing in Cyanobacteria by Homoserine Lactones: The Origin of Blooms". In: Water 2021, Vol. 13, Page 1831 13.13, p. 1831. ISSN: 20734441. DOI: 10 .3390/W13131831. URL: https : / /www . mdpi . com/2073-4441/13/13/ 1831/htm\%20https://www.mdpi.com/2073-4441/13/13/1831.

Hodgskiss, Malcolm S.W., Peter W. Crockford, Yongbo Peng, Boswell A. Wing, and Tristan J. Horner (2019). "A productivity collapse to end Earth's Great Oxidation". In: Proceedings of the National Academy of Sciences of the United States of America 116.35, pp. 17207-17212. ISSN: 10916490. DOI: 10.1073/PNAS . 1900325116/-/DCSUPPLEMENTAL. URL: https://www.pnas .org/content/116/35/ 17207\%20https://www. pnas .org/content/116/35/17207. abstract.

Homann, Martin, Christoph Heubeck, Alessandro Airo, and Michael M. Tice (2015). "Morphological adaptations of 3.22 Ga-old tufted microbial mats to Archean coastal habitats (Moodies Group, Barberton Greenstone Belt, South Africa)". In: Precambrian Research 266, pp. 47-64. ISSN: 03019268. DOI: 10.1016/J . PRECAMRES . 2015.04.018.

Homann, Martin, Pierre Sansjofre, Mark Van Zuilen, Christoph Heubeck, Jian Gong, Bryan Killingsworth, Ian S. Foster, Alessandro Airo, Martin J. Van Kranendonk, Magali Ader, and Stefan V. Lalonde (2018). "Microbial life and biogeochemical cycling on land 3,220 million years ago". In: Nature Geoscience 11.9, pp. 665-671. ISSN: 17520908. DOI: 10.1038/S41561-018-0190-9.

Huang, Yili, Yanhua Zeng, Hao Feng, Yuehong Wu, and Xuewei Xu (2015). "Croceicoccus naphthovorans sp. nov., a polycyclic aromatic hydrocarbons-degrading and acylhomoserine-lactoneproducing bacterium isolated from marine biofilm, and emended description of the genus croceicoccus". In: International Journal of Systematic and Evolutionary Microbiology 65.5, pp. 15311536. ISSN: 14665026. DOI: 10 . 1099 / IJS . 0 . 000132 / CITE / REFWORKS. URL: https : / / www . microbiologyresearch.org/content/journal/ijsem/10.1099/ijs.0.000132.

Hyatt, Doug, Gwo-Liang Chen, Philip F LoCascio, Miriam L Land, Frank W Larimer, and Loren J Hauser (2010). "Prodigal: prokaryotic gene recognition and translation initiation site identification". In: BMC Bioinformatics 2010 11:1 11.1, pp. 1-11. ISSN: 1471-2105. DOI: 10.1186/1471-2105-11119. URL: https://bmcbioinformatics . biomedcentral . com/articles/10 .1186/1471-210511-119.

Imhoff, Johannes F. (2014). "The Family Chromatiaceae". In: The Prokaryotes. Berlin, Heidelberg: Springer Berlin Heidelberg, pp. 151-178. DOI: 10.1007/978-3-642-38922-1\{\_\}295.

Jelen, Benjamin I., Donato Giovannelli, and Paul G. Falkowski (2016). "The Role of Microbial Electron Transfer in the Coevolution of the Biosphere and Geosphere". In: Annual Review of Microbiology 70, pp. 45-62. ISSN: 15453251. DOI: 10.1146/ANNUREV-MICRO-102215-095521/SUPPL\{\_\}FILE/ 
MI70\{\_\}FALKOWSKI $\left\{\backslash_{-}\right\}$SUPTABLES.PDF. URL: https ://www-annualreviews-org.pbidi. unam . $\mathrm{mx}: 2443 / \mathrm{doi} / \mathrm{abs} / 10.1146 /$ annurev-micro-102215-095521.

Jiang, Rong, Meie Wang, Weiping Chen, Xuzhi Li, and María Balseiro-Romero (2020). "Changes in the integrated functional stability of microbial community under chemical stresses and the impacting factors in field soils". In: Ecological Indicators 110, p. 105919. ISSN: 1470-160X. DOI: $10.1016 / \mathrm{J}$. ECOLIND. 2019.105919.

Jousset, Alexandre, Christina Bienhold, Antonis Chatzinotas, Laure Gallien, Angélique Gobet, Viola Kurm, Kirsten Küsel, Matthias C. Rillig, Damian W. Rivett, Joana F. Salles, Marcel G.A. Van Der Heijden, Noha H. Youssef, Xiaowei Zhang, Zhong Wei, and Gera W.H. Hol (2017). "Where less may be more: how the rare biosphere pulls ecosystems strings". In: The ISME Journal 2017 11:4 11.4, pp. 853-862. ISSN: 1751-7370. DOI: 10.1038/ismej .2016.174. URL: https://www. nature . com/articles/ismej2016174.

Kanehisa, Minoru, Yoko Sato, Masayuki Kawashima, Miho Furumichi, and Mao Tanabe (2016). "KEGG as a reference resource for gene and protein annotation". In: Nucleic Acids Research 44.D1, pp. D457-D462. ISSN: 0305-1048. DOI: 10.1093/NAR/GKV1070. URL: https://academic . oup.com/nar/article/44/D1/D457/2502600.

Kolda, Anamarija, Ines Petrić, Maja Mucko, Sanja Gottstein, Petar Žutinić, Gordana Goreta, Ivančica Ternjej, Josip Rubinić, Maja Radišić, and Marija Gligora Udovič (2019). "How environment selects: Resilience and survival of microbial mat community within intermittent karst spring Krčić (Croatia)". In: Ecohydrology 12.2. ISSN: 19360592. DOI: 10.1002/eco.2063.

Koneswarakantha, Bjoern (2021a). easyalluvial: Generate Alluvial Plots with a Single Line of Code. URL: https://CRAN.R-project .org/package=easyalluvial.

- (2021b). parcats: Interactive Parallel Categories Diagrams for 'easyalluvial'. URL: https://CRAN. Rproject. org $/$ package=parcats.

Konhauser, Kurt O., Leslie J. Robbins, Ernesto Pecoits, Caroline Peacock, Andreas Kappler, and Stefan V. Lalonde (2015). "The Archean Nickel Famine Revisited". In: https://home.liebertpub.com/ast 15.10, pp. 804-815. ISSN: 15311074. DOI: 10 . 1089 / AST . 2015 . 1301. URL: https : / / www . liebertpub.com/doi/abs/10.1089/ast.2015.1301.

Kuever, Jan (2014). "The Family Desulfohalobiaceae". In: The Prokaryotes. Berlin, Heidelberg: Springer Berlin Heidelberg. DOI: 10.1007/978-3-642-39044-9\{\_\}311.

Kurth, Daniel, Dario Elias, Maria Cecilia Rasuk, Manuel Contreras, and Maria Eugenia Farias (2021). "Carbon fixation and rhodopsin systems in microbial mats from hypersaline lakes Brava and Tebenquiche, Salar de Atacama, Chile". In: PLOS ONE 16.2, e0246656. ISSN: 1932-6203. DOI: 10.1371/JOURNAL. PONE. 0246656. URL: https://journals.plos.org/plosone/article?id=10. 1371/journal . pone. 0246656.

Landi, Simone, Roberta Nurcato, Alessia De Lillo, Marco Lentini, Stefania Grillo, and Sergio Esposito (2016). "Glucose-6-phosphate dehydrogenase plays a central role in the response of tomato (Solanum lycopersicum) plants to short and long-term drought". In: Plant Physiology and Biochemistry 105, pp. 79-89. ISSN: 0981-9428. DOI: 10.1016/J.PLAPHY.2016.04.013.

Le, Phuong Thi, Thulani P. Makhalanyane, Leandro D. Guerrero, Surendra Vikram, Yves Van De Peer, and Don A. Cowan (2016). "Comparative Metagenomic Analysis Reveals Mechanisms for Stress Response in Hypoliths from Extreme Hyperarid Deserts". In: Genome Biology and Evolution 8.9, pp. 2737-2747. ISSN: 17596653. DOI: 10.1093/GBE/EVW189. URL: https : //academic . oup.com/ gbe/article/8/9/2737/2236390.

Lepot, Kevin (2020). "Signatures of early microbial life from the Archean (4 to $2.5 \mathrm{Ga}$ ) eon". In: Earth-Science Reviews 209, p. 103296. ISSN: 00128252. DOI: 10.1016/j.earscirev.2020.103296. 
Lex, Alexander, Nils Gehlenborg, Hendrik Strobelt, Romain Vuillemot, and Hanspeter Pfister (2014). "UpSet: Visualization of intersecting sets". In: IEEE Transactions on Visualization and Computer Graphics 20.12, pp. 1983-1992. ISSN: 10772626. DOI: 10.1109/TVCG.2014.2346248.

Li, Dinghua, Chi-Man Liu, Ruibang Luo, Kunihiko Sadakane, and Tak-Wah Lam (2015). "MEGAHIT: an ultra-fast single-node solution for large and complex metagenomics assembly via succinct de Bruijn graph". In: Bioinformatics 31.10, pp. 1674-1676. ISSN: 1367-4803. DOI: 10 . 1093 / BIOINFORMATICS/BTV033. URL: https://academic.oup.com/bioinformatics/article/31/10/ $1674 / 177884$.

Li, Guangyu, Xiang Zeng, Xiupian Liu, Xiaobo Zhang, and Zongze Shao (2016). "Wukongibacter baidiensis gen. Nov., sp. Nov., an anaerobic bacterium isolated from hydrothermal sulfides, and proposal for the reclassification of the closely related clostridium halophilum and clostridium caminithermale within maledivibacter gen. Nov. and Paramaledivibacter gen. Nov., respectively". In: International Journal of Systematic and Evolutionary Microbiology 66.11, pp. 4355-4361. ISSN: 14665026. DOI: 10 . 1099/IJSEM . 0 . 001355/CITE/REFWORKS. URL: https : / / ww . microbiologyresearch . org/ content/journal/ijsem/10.1099/ijsem.0.001355.

Li, Heng, Bob Handsaker, Alec Wysoker, Tim Fennell, Jue Ruan, Nils Homer, Gabor Marth, Goncalo Abecasis, Richard Durbin, and 1000 Genome Project Data Processing Subgroup (2009). "The Sequence Alignment/Map format and SAMtools". In: Bioinformatics 25.16, pp. 2078-2079. ISSN: 1367-4803. DOI: 10 . 1093/BIOINFORMATICS / BTP352. URL: https : / / academic . oup . com / bioinformatics/article/25/16/2078/204688.

López-Lozano, Nguyen E., Luis E. Eguiarte, Germán Bonilla-Rosso, Felipe García-Oliva, Celeste Martínez-Piedragil, Christine Rooks, and Valeria Souza (2012). "Bacterial Communities and the Nitrogen Cycle in the Gypsum Soils of Cuatro Ciénegas Basin, Coahuila: A Mars Analogue". In: https://home.liebertpub.com/ast 12.7, pp. 699-709. ISSN: 15311074. DOI: 10.1089/AST . 2012.0840. URL: https://www.liebertpub.com/doi/abs/10.1089/ast.2012.0840.

Love, Michael I., Wolfgang Huber, and Simon Anders (2014). "Moderated estimation of fold change and dispersion for RNA-seq data with DESeq2". In: Genome Biology 15.12, pp. 1-21. ISSN: 1474760X. DOI: 10.1186/S13059-014-0550-8/FIGURES/9. URL: https://genomebiology . biomedcentral . com/articles/10.1186/s13059-014-0550-8.

Lowe, Donald R., Gary R. Byerly, and Frank T. Kyte (2014). "Recently discovered 3.42-3.23 Ga impact layers, Barberton Belt, South Africa: 3.8 Ga detrital zircons, Archean impact history, and tectonic implications". In: Geology 42.9, pp. 747-750. ISSN: 0091-7613. DOI: 10.1130/G35743.1.

Marcondes de Souza, Jackson Antônio, Lucia Maria Carareto Alves, Alessandro de Mello Varani, and Eliana Gertrudes de Macedo Lemos (2014). "The Family Bradyrhizobiaceae". In: The Prokaryotes. Berlin, Heidelberg: Springer Berlin Heidelberg, pp. 135-154. DOI: 10.1007/978-3-642-30197$1\left\{\backslash \_\right\} 253$.

Mardanov, Andrey V., Alexey V. Beletsky, Nikolai V. Ravin, Ekaterina A. Botchkova, Yuriy V. Litti, and Alla N. Nozhevnikova (2019). "Genome of a novel bacterium "candidatus jettenia ecosi" reconstructed from the metagenome of an anammox bioreactor". In: Frontiers in Microbiology 10.OCT, p. 2442. ISSN: 1664302X. DOI: 10.3389/FMICB.2019.02442/BIBTEX.

Medina-Chávez, Nahui Olin, Mariette Viladomat-Jasso, Gabriela Olmedo-Álvarez, Luis E. Eguiarte, Valeria Souza, and Susana De La Torre Zavala (2019). "Diversity of Archaea Domain in Cuatro Cienegas Basin: Archaean Domes". In: bioRxiv, p. 766709. ISSN: 2692-8205. DOI: 10.1101/766709. URL: https://www . biorxiv . org/content/10.1101/766709v1\%20https: //www . biorxiv . org/ content/10.1101/766709v1.abstract.

Meijenfeldt, F. A. Bastiaan von, Ksenia Arkhipova, Diego D. Cambuy, Felipe H. Coutinho, and Bas E. Dutilh (2019). "Robust taxonomic classification of uncharted microbial sequences and bins with 
CAT and BAT". In: Genome Biology 2019 20:1 20.1, pp. 1-14. ISSN: 1474-760X. DOI: 10.1186/ S13059-019-1817-X. URL: https://genomebiology . biomedcentral . com/articles/10.1186/ s13059-019-1817-x.

Miranda, Priscilla J., Nathan K. McLain, Roland Hatzenpichler, Victoria J. Orphan, and Jesse G. Dillon (2016). "Characterization of chemosynthetic microbial mats associated with intertidal hydrothermal sulfur vents in white point, San Pedro, CA, USA". In: Frontiers in Microbiology 7.JUL, p. 1163. ISSN: 1664302X. DOI: 10.3389/FMICB.2016.01163/BIBTEX.

Mistry, Jaina, Sara Chuguransky, Lowri Williams, Matloob Qureshi, Gustavo A Salazar, Erik L L Sonnhammer, Silvio C E Tosatto, Lisanna Paladin, Shriya Raj, Lorna J Richardson, Robert D Finn, and Alex Bateman (2021). "Pfam: The protein families database in 2021". In: Nucleic Acids Research 49.D1, pp. D412-D419. ISSN: 0305-1048. DOI: 10 . 1093 / NAR / GKAA913. URL: https : //academic. oup.com/nar/article/49/D1/D412/5943818.

Mole, David R., Stephen J. Barnes, Zhuosen Yao, Alistair J.R. White, R. Maas, and Christopher L. Kirkland (2018). "The Archean Fortescue large igneous province: A result of komatiite contamination by a distinct Eo-Paleoarchean crust". In: Precambrian Research 310, pp. 365-390. ISSN: 0301-9268. DOI: 10.1016/J . PRECAMRES . 2018.02 .017. URL: https://espace . curtin . edu .au/ handle/20.500.11937/68162.

Moore, Eli K., Benjamin I. Jelen, Donato Giovannelli, Hagai Raanan, and Paul G. Falkowski (2017). "Metal availability and the expanding network of microbial metabolisms in the Archaean eon". In: Nature Geoscience 2017 10:9 10.9, pp. 629-636. ISSN: 1752-0908. DOI: 10.1038/NGE03006. URL: https://www-nature-com.pbidi.unam.mx:2443/articles/ngeo3006.

Moreno-Letelier, Alejandra, Gabriela Olmedo-Alvarez, Luis E. Eguiarte, and Valeria Souza (2012). "Divergence and Phylogeny of Firmicutes from the Cuatro Ciénegas Basin, Mexico: A Window to an Ancient Ocean". In: https://home.liebertpub.com/ast 12.7, pp. 674-684. ISSN: 15311074. DOI: 10.1089/AST . 2011.0685. URL: https://www. liebertpub.com/doi/abs/10.1089/ast. 2011. 0685.

Nakazawa, Minato (2021). fmsb: Functions for Medical Statistics Book with some Demographic Data. URL: https : //CRAN .R-project. org/package =fmsb.

NCBI Resource Coordinators (2018). "Database resources of the National Center for Biotechnology Information". In: Nucleic Acids Research 46.D1, pp. D8-D13. ISSN: 0305-1048. DOI: 10.1093/NAR/ GKX1095. URL: https://academic.oup.com/nar/article/46/D1/D8/4621330.

Netz, Natalie and Till Opatz (2015). "Marine Indole Alkaloids". In: Marine Drugs 13.8, p. 4814. ISSN: 16603397. DOI: 10 . 3390 / MD13084814. URL: /pmc / articles / PMC4557006 / \%20 / pmc / articles/PMC4557006/?report=abstract\%20https://www.ncbi.nlm.nih.gov/pmc/articles/ PMC4557006/.

Noffke, Nora (2010). Geobiology: Microbial Mats in Sandy Deposits from the Archean Era to Today. Berlin, Heidelberg: Springer Berlin Heidelberg. ISBN: 978-3-642-12771-7. DOI: 10 . 1007/978-3642-12772-4.

Noffke, Nora, Daniel Christian, David Wacey, and Robert M. Hazen (2013). "Microbially induced sedimentary structures recording an ancient ecosystem in the ca. 3.48 Billion-year-old dresser formation, pilbara, Western Australia". In: Astrobiology 13.12, pp. 1103-1124. ISSN: 15311074. DOI: 10 . 1089 / AST . 2013 . 1030 / ASSET / IMAGES / LARGE / FIGURE19 . JPEG. URL: https : / / ww . liebertpub.com/doi/abs/10.1089/ast.2013.1030.

Noffke, Nora, Kenneth A. Eriksson, Robert M. Hazen, and Edward L. Simpson (2006). "A new window into Early Archean life: Microbial mats in Earth's oldest siliciclastic tidal deposits (3.2 Ga Moodies Group, South Africa)". In: Geology 34.4, pp. 253-256. ISSN: 0091-7613. DOI: 10.1130/G22246.1. 
Obridko, Vladimir N., Maria V. Ragulskaya, and Elizaveta G. Khramova (2020). "Young Sun, galactic processes, and origin of life". In: Journal of Atmospheric and Solar-Terrestrial Physics 208, p. 105395. ISSN: 1364-6826. DOI: 10.1016/J. JASTP.2020.105395.

Okonkwo, Onyinye, Renaud Escudie, Nicolas Bernet, Rahul Mangayil, Aino Maija Lakaniemi, and Eric Trably (2020). "Bioaugmentation enhances dark fermentative hydrogen production in cultures exposed to short-term temperature fluctuations". In: Applied Microbiology and Biotechnology 104.1, pp. 439-449. ISSN: 14320614. DOI: 10.1007/S00253-019-10203-8/FIGURES/5. URL: https : //link. springer.com/article/10.1007/s00253-019-10203-8.

Oksanen, Jari, F Guillaume Blanchet, Michael Friendly, Roeland Kindt, Pierre Legendre, Dan McGlinn, Peter R Minchin, R B O'Hara, Gavin L Simpson, Peter Solymos, M Henry H Stevens, Eduard Szoecs, and Helene Wagner (2020). vegan: Community Ecology Package. URL: https : //CRAN.R-project.org/package=vegan.

Oren, Aharon (2014). "The Family Methanosarcinaceae". In: The Prokaryotes. Berlin, Heidelberg: Springer Berlin Heidelberg, pp. 259-281. DOI: 10.1007/978-3-642-38954-2\{\_\}408.

Parsek, Matthew R., Dale L. Val, Brian L. Hanzelka, John E. Cronan, and E. P. Greenberg (1999). "Acyl homoserine-lactone quorum-sensing signal generation". In: Proceedings of the National Academy of Sciences 96.8, pp. 4360-4365. ISSN: 0027-8424. DOI: 10.1073/PNAS.96.8.4360. URL: https ://www . pnas . org/content/96/8/4360\%20https ://www . pnas . org/content/96/8/4360. abstract.

Pascoal, Francisco, Rodrigo Costa, and Catarina Magalhães (2021). "The microbial rare biosphere: current concepts, methods and ecological principles". In: FEMS Microbiology Ecology 97.1, p. 227. ISSN: 0168-6496. DOI: 10 . 1093/FEMSEC/FIAA227. URL: https : / / academic . oup . com/femsec/ article/97/1/fiaa227/5974270.

Pedersen, Thomas Lin (2020). patchwork: The Composer of Plots. URL: https://CRAN.R-project . org/package=patchwork.

Pennekamp, Frank, Mikael Pontarp, Andrea Tabi, Florian Altermatt, Roman Alther, Yves Choffat, Emanuel A. Fronhofer, Pravin Ganesanandamoorthy, Aurélie Garnier, Jason I. Griffiths, Suzanne Greene, Katherine Horgan, Thomas M. Massie, Elvira Mächler, Gian Marco Palamara, Mathew Seymour, and Owen L. Petchey (2018). "Biodiversity increases and decreases ecosystem stability". In: Nature 2018 563:7729 563.7729, pp. 109-112. ISSN: 1476-4687. DOI: 10.1038/s41586-0180627-8. URL: https://www nature.com/articles/s41586-018-0627-8.

Perl, Scott M. and Bonnie K. Baxter (2020). "Great Salt Lake as an Astrobiology Analogue for Ancient Martian Hypersaline Aqueous Systems". In: Great Salt Lake Biology, pp. 487-514. DOI: 10.1007/ 978-3-030-40352-2\{\_\}16. URL: https://link.springer.com/chapter/10.1007/978-3-03040352-2_16.

Peschel, Stefanie, Christian L. Müller, Erika von Mutius, Anne Laure Boulesteix, and Martin Depner (2021). "NetCoMi: network construction and comparison for microbiome data in R". In: Briefings in Bioinformatics 22.4, pp. 1-18. ISSN: 14774054. DOI: 10.1093/BIB/BBAA290. URL: https : //academic.oup.com/bib/article/22/4/bbaa290/6017455.

Pett-Ridge, J and M K Firestone (2005). "Redox fluctuation structures microbial communities in a wet tropical soil". In: Applied and Environmental Microbiology 71.11, pp. 6998-7007. ISSN: 00992240. DOI: $10.1128 / A E M .71$.11 .6998-7007 . 2005/ASSET/AEEDB38D-8F74-4841-BB29-3E8420CB32E0/ ASSETS / GRAPHIC / ZAM0110560800004 . JPEG. URL: https : // journals . asm . org/doi / abs / 10 . 1128/AEM.71.11.6998-7007.2005.

Poulton, Simon W., Andrey Bekker, Vivien M. Cumming, Aubrey L. Zerkle, Donald E. Canfield, and David T. Johnston (2021). "A 200-million-year delay in permanent atmospheric oxygenation". In: 
Nature 2021 592:7853 592.7853, pp. 232-236. ISSN: 1476-4687. DOI: 10.1038/s41586-021-03393-

7. URL: https://www. nature.com/articles/s41586-021-03393-7.

Prieto-Barajas, Cristina M., Eduardo Valencia-Cantero, and Gustavo Santoyo (2018). "Microbial mat ecosystems: Structure types, functional diversity, and biotechnological application". In: Electronic Journal of Biotechnology 31, pp. 48-56. ISSN: 0717-3458. DOI: 10.1016/J.EJBT.2017.11.001.

Purdy, Kevin J. (2005). "Nucleic Acid Recovery from Complex Environmental Samples". In: Methods in Enzymology 397, pp. 271-292. ISSN: 0076-6879. DOI: 10.1016/S0076-6879(05)97016-X.

R Core Team (2020). R: A Language and Environment for Statistical Computing. Vienna, Austria.

Rainey, Paul B. and Michael Travisano (1998). "Adaptive radiation in a heterogeneous environment". In: Nature 1998 394:6688 394.6688, pp. 69-72. ISSN: 1476-4687. DOI: 10.1038/27900. URL: https: //www. nature.com/articles/27900.

Ramos, Vitor M.C., Raquel Castelo-Branco, Pedro N. Leão, Joana Martins, Sinda Carvalhal-Gomes, Frederico Sobrinho da Silva, João G.Mendonça Filho, and Vitor M. Vasconcelos (2017). "Cyanobacterial diversity in microbial mats from the hypersaline lagoon system of Araruama, Brazil: An in-depth polyphasic study". In: Frontiers in Microbiology 8.JUN, p. 1233. ISSN: 1664302X. DOI: 10.3389/FMICB. 2017.01233/BIBTEX.

Rassa, Allen C., Sean M. McAllister, Sarah A. Safran, and Craig L. Moyer (2009). "Zeta-Proteobacteria Dominate the Colonization and Formation of Microbial Mats in Low-Temperature Hydrothermal Vents at Loihi Seamount, Hawaii". In: https://doi.org/10.1080/01490450903263350 26.8, pp. 623 638. ISSN: 01490451. DOI: 10.1080/01490450903263350. URL: https ://www.tandfonline.com/ doi/abs/10.1080/01490450903263350.

Reinold, Max, Hon Lun Wong, Fraser I. MacLeod, Julia Meltzer, April Thompson, and Brendan P. Burns (2019). "The Vulnerability of Microbial Ecosystems in a Changing Climate: Potential Impact in Shark Bay". In: Life 9.3. ISSN: 20751729. DOI: 10.3390/LIFE9030071. URL: /pmc/articles/ PMC6789446/\%20/pmc/articles/PMC6789446/?report=abstract\%20https : //www . ncbi . nlm . nih.gov/pmc/articles/PMC6789446/.

Ren, Ze, Xiaodong Qu, Min Zhang, Yang Yu, and Wenqi Peng (2019). "Distinct bacterial communities in wet and dry seasons during a seasonal water level fluctuation in the largest freshwater lake (Poyang Lake) in China". In: Frontiers in Microbiology 10.MAY, p. 1167. ISSN: 1664302X. DOI: 10.3389/FMICB. 2019.01167/BIBTEX.

Robinson, Mark D., Davis J. McCarthy, and Gordon K. Smyth (2010). "edgeR: a Bioconductor package for differential expression analysis of digital gene expression data". In: Bioinformatics 26.1, pp. 139 140. ISSN: 1367-4803. DOI: 10.1093/BIOINFORMATICS/BTP616. URL: https://academic .oup.com/ bioinformatics/article/26/1/139/182458.

Röttjers, Lisa and Karoline Faust (2018). "From hairballs to hypotheses-biological insights from microbial networks". In: FEMS Microbiology Reviews 42.6, pp. 761-780. ISSN: 0168-6445. DOI: 10 . 1093/FEMSRE/FUY030. URL: https://academic.oup.com/femsre/article/42/6/761/5061627.

Rudis, Bob (2019). streamgraph: streamgraph is an htmlwidget for building streamgraph visualizations. URL: http://github.com/hrbrmstr/streamgraph.

Salaemae, Wanisa, Grant W. Booker, and Steven W. Polyak (2016). "The Role of Biotin in Bacterial Physiology and Virulence: a Novel Antibiotic Target for Mycobacterium tuberculosis ". In: Microbiology Spectrum 4.2. ISSN: 2165-0497. DOI: 10.1128/MICROBIOLSPEC. VMBF-0008-2015/ASSET/ 6E6092E4-2127-40B3-B0C6-03D36FC7B86E/ASSETS/GRAPHIC/VMBF-0008-2015-FIG7 . GIF. URL: https://journals.asm.org/doi/abs/10.1128/microbiolspec.VMBF-0008-2015.

Saona, Luis A., Mariana Soria, Patricio G. Villafañe, Agustina I. Lencina, Tatiana Stepanenko, and María E. Farías (2020). "Andean Microbial Ecosystems: Traces in Hypersaline Lakes About Life 
Origin". In: pp. 167-181. DOI: 10 . 1007/978-3-030-46087-7\{\_\}8. URL: https : / / link . springer. com/chapter/10.1007/978-3-030-46087-7_8.

Schopf, J. William (2011). "The paleobiological record of photosynthesis". In: Photosynthesis research 107.1, pp. 87-101. ISSN: 1573-5079. DOI: 10.1007/S11120-010-9577-1. URL: https://pubmed . ncbi.nlm.nih.gov/20607406/.

Shade, Ashley, Hannes Peter, Steven D Allison, Didier Baho, Mercé Berga, Helmut Buergmann, David H Huber, Silke Langenheder, Jay T Lennon, Jennifer BH Martiny, Kristin L Matulich, Thomas M Schmidt, and Jo Handelsman (2012). "Fundamentals of Microbial Community Resistance and Resilience". In: Frontiers in Microbiology 0.DEC, p. 417. ISSN: 1664-302X. DOI: 10.3389/FMICB. 2012.00417.

Silva, Genivaldo Gueiros Z., Kevin T. Green, Bas E. Dutilh, and Robert A. Edwards (2016). "SUPERFOCUS: a tool for agile functional analysis of shotgun metagenomic data". In: Bioinformatics 32.3, pp. 354-361. ISSN: 1367-4803. DOI: 10.1093/BIOINFORMATICS/BTV584. URL: https://academic . oup.com/bioinformatics/article/32/3/354/1743726.

Sohm, Jill A., Thomas D. Niederberger, Alexander E. Parker, Joëlle Tirindelli, Troy Gunderson, Stephen Craig Cary, Douglas G. Capone, and Edward J. Carpenter (2020). "Microbial Mats of the McMurdo Dry Valleys, Antarctica: Oases of Biological Activity in a Very Cold Desert". In: Frontiers in Microbiology 11, p. 2599. ISSN: 1664302X. DOI: 10.3389/FMICB. 2020.537960/BIBTEX.

Song, Hyun-Seob, Ryan S. Renslow, Jim K. Fredrickson, and Stephen R. Lindemann (2015). "Integrating Ecological and Engineering Concepts of Resilience in Microbial Communities". In: Frontiers in Microbiology 0.DEC, p. 1298. ISSN: 1664-302X. DOI: 10.3389/FMICB.2015.01298.

Souza, Valeria, Janet L. Siefert, Ana E. Escalante, James J. Elser, and Luis E. Eguiarte (2012). "The Cuatro Ciénegas Basin in Coahuila, Mexico: An Astrobiological Precambrian Park". In: https://home.liebertpub.com/ast 12.7, pp. 641-647. ISSN: 15311074. DOI: 10.1089/AST . 2011.0675. URL: https://www.liebertpub.com/doi/abs/10.1089/ast.2011.0675.

Tajika, Eiichi (2007). "Long-term stability of climate and global glaciations throughout the evolution of the Earth". In: Earth, Planets and Space 2007 59:4 59.4, pp. 293-299. ISSN: 1880-5981. DOI: 10.1186/BF03353107. URL: https : / / link. springer . com/articles /10 . 1186/BF03353107\% 20https://link. springer.com/article/10.1186/BF03353107.

Thompson, Luke R., Qinglu Zeng, Libusha Kelly, Katherine H. Huang, Alexander U. Singer, Jo Anne Stubbe, and Sallie W. Chisholm (2011). "Phage auxiliary metabolic genes and the redirection of cyanobacterial host carbon metabolism". In: Proceedings of the National Academy of Sciences of the United States of America 108.39, E757-E764. ISSN: 00278424. DOI: 10.1073/PNAS.1102164108//DCSUPPLEMENTAL. URL: https://www. pnas . org/content/108/39/E757\%20https://www . pnas . org/content/108/39/E757. abstract.

Tice, Michael M. (2009). "Environmental Controls on Photosynthetic Microbial Mat Distribution and Morphogenesis on a 3.42 Ga Clastic-Starved Platform". In: Astrobiology 9.10, pp. 989-1000. ISSN: 1531-1074. DOI: 10.1089/ast.2008.0330.

Tice, Michael M. and Donald R. Lowe (2004). "Photosynthetic microbial mats in the 3,416-Myrold ocean". In: Nature 2004 431:7008 431.7008, pp. 549-552. ISSN: 1476-4687. DOI: 10 . 1038 / nature02888. URL: https://www.nature.com/articles/nature02888.

Varin, Thibault, Connie Lovejoy, Anne D. Jungblut, Warwick F. Vincent, and Jacques Corbeil (2012). "Metagenomic Analysis of Stress Genes in Microbial Mat Communities from Antarctica and the High Arctic". In: Applied and Environmental Microbiology 78.2, p. 549. ISSN: 00992240. DOI: 10. 1128 / AEM . 06354 - 11. URL: /pmc / articles / PMC3255749 /\%20 / pmc / articles / PMC3255749 / ?report=abstract\%20https://www.ncbi.nlm.nih.gov/pmc/articles/PMC3255749/. 
Visscher, Pieter T., Kimberley L. Gallagher, Anthony Bouton, Maria E. Farias, Daniel Kurth, Maria Sancho-Tomás, Pascal Philippot, Andrea Somogyi, Kadda Medjoubi, Emmanuelle Vennin, Raphaël Bourillot, Malcolm R. Walter, Brendan P. Burns, Manuel Contreras, and Christophe Dupraz (2020). "Modern arsenotrophic microbial mats provide an analogue for life in the anoxic Archean". In: Communications Earth \& Environment 2020 1:1 1.1, pp. 1-10. ISSN: 2662-4435. DOI: 10.1038 / s43247-020-00025-2. URL: https://www . nature.com/articles/s43247-020-00025-2.

Warwick-Dugdale, Joanna, Holger H. Buchholz, Michael J. Allen, and Ben Temperton (2019). "Hosthijacking and planktonic piracy: how phages command the microbial high seas". In: Virology Journal 2019 16:1 16.1, pp. 1-13. ISSN: 1743-422X. DOI: 10.1186/S12985-019-1120-1. URL: https: //virologyj.biomedcentral.com/articles/10.1186/s12985-019-1120-1.

Wickham, Hadley (2016). ggplot2: Elegant Graphics for Data Analysis. Springer-Verlag New York. ISBN: 978-3-319-24277-4. URL: https://ggplot2.tidyverse.org.

- (2021). tidyr: Tidy Messy Data. URL: https://CRAN.R-project.org/package=tidyr.

Wickham, Hadley, Romain François, Lionel Henry, and Kirill Müller (2021). dplyr: A Grammar of Data Manipulation. URL: https ://CRAN.R-project.org/package=dplyr.

Wong, Hon Lun, Fraser I. MacLeod, Richard Allen White, Pieter T. Visscher, and Brendan P. Burns (2020). "Microbial dark matter filling the niche in hypersaline microbial mats". In: Microbiome 2020 8:1 8.1, pp. 1-14. ISSN: 2049-2618. DOI: 10 . 1186/S40168-020-00910-0. URL: https : //microbiomejournal.biomedcentral.com/articles/10.1186/s40168-020-00910-0.

Wong, Hon Lun, Daniela Lee Smith, Pieter T. Visscher, and Brendan P. Burns (2015). "Niche differentiation of bacterial communities at a millimeter scale in Shark Bay microbial mats". In: Scientific Reports 2015 5:1 5.1, pp. 1-17. ISSN: 2045-2322. DOI: 10.1038/srep15607. URL: https: //www.nature.com/articles/srep15607.

Wong, Hon Lun, Richard Allen White, Pieter T. Visscher, James C. Charlesworth, Xabier VázquezCampos, and Brendan P. Burns (2018). "Disentangling the drivers of functional complexity at the metagenomic level in Shark Bay microbial mat microbiomes". In: The ISME Journal 2018 12:11 12.11, pp. 2619-2639. ISSN: 1751-7370. DOI: 10.1038/s41396-018-0208-8. URL: https : //www. nature.com/articles/s41396-018-0208-8.

Yan, Hui, Lei Zhu, Yingjun Wang, Sen Zhang, Pei Liu, Tina T. X. Dong, Qinan Wu, and Jin-Ao Duan (2021). "Comparative metagenomics analysis of the rhizosphere microbiota influence on Radix Angelica sinensis in different growth soil environments in China". In: Food Science and Technology. ISSN: 0101-2061. DOI: 10 . 1590 /FST . 65120. URL: http : / / www . scielo . br / j/cta / a / yzqmHYfCzjWwwPXtwjTT7Th/?lang=en. 